\title{
Direct Strength Method for calculating distortional buckling capacity of cold-formed thin-walled steel columns with uniform and non-uniform elevated temperatures
}

\author{
Ashkan Shahbazian, Yong Chang Wang* \\ School of Mechanical, Aerospace and Civil Engineering, The University of Manchester, Pariser Building, Sackville Street, Manchester M13 9PL, United Kingdom
}

\section{A R T I C L E I N F O}

\section{Article history:}

Received 14 October 2011

Received in revised form

6 January 2012

Accepted 6 January 2012

\section{Keywords:}

Steel

Cold-formed

Thin-walled

Direct Strength Method

Distortional buckling

Fire resistance

Numerical modelling

Non-uniform elevated temperature

Uniform elevated temperature

\begin{abstract}
A B S T R A C T
This paper assesses the applicability of the Direct Strength Method (DSM) to calculating the distortional buckling strength of cold-formed thin-walled (CF-TW) steel members with uniform and non-uniform elevated temperature distributions in the cross-section. The assessment was carried out by checking the DSM calculation results with numerical simulation results using the general finite element software ABAQUS which was further validated against ambient and uniform elevated temperature tests on short lipped channel sections, in addition to the author's previous validation studies for thin-walled steel columns with non-uniform temperature distributions. The validated numerical model has been used to generate an extensive database (453) of numerical results of load carrying capacity of CF-TW members with different uniform and non-uniform temperature distributions in the cross-sections, under different boundary and loading conditions and with different dimensions and lengths. It is concluded that the existing DSM distortional buckling curve for ambient temperature application is also applicable for columns with uniform temperature distributions in the cross-section, but is unconservative for columns with non-uniform temperature distributions in the cross-section. This paper proposes a modification to the distortional buckling curve to enable DSM to deal with distortional buckling in columns with non-uniform temperature distributions.
\end{abstract}

(c) 2012 Elsevier Ltd. All rights reserved.

\section{Introduction}

The use of cold-formed thin-walled (CF-TW) steel structures in both industrial and residential constructions has grown in recent years, mainly because unusual cross-section configurations can be produced economically, in addition to their lightness and ease of fabrication. Predicting the ultimate strength of such profiles at both ambient and elevated temperatures is important for structural engineers. For predicting the load carrying capacity of CF-TW steel structural members, the effective width method is traditionally followed, but in recent years the Direct Strength Method (DSM) [1] is becoming more popular as it avoids lengthy calculations of the effective widths. This new method now has been adopted by AISI [2] for ambient temperature applications.

For CF-TW steel members exposed to fire condition from one side, using the effective width method is calculation-intensive and timeconsuming because of the non-uniform distributions of mechanical properties of steel, which is a result of non-uniform temperature distributions in the cross-section. Using DSM would be particularly advantageous, especially when dealing with optimised cross-sections

\footnotetext{
*Corresponding author. Tel.: +441613068968.

E-mail address: yong.wang@manchester.ac.uk (Y.C. Wang).
}

such as lipped channels with multiple stiffeners. For example, Fig. 1 shows how the critical buckling loads of a column may be improved using web stiffeners in the cross-section. In the conventional effective width method, the need to divide the cross-section into many plate elements makes the calculations a complex process when the mechanical properties of the plates are not uniform under nonuniform temperatures in the cross-section. In two related research papers recently published by the authors [3,4], the Direct Strength Method (DSM) has been successfully applied to dealing with thinwalled steel columns with non-uniform temperature distributions in the cross-sections for global and local buckling. This paper continues this series of research and applies DSM to distortional buckling.

DSM is an extension of the column buckling curve for global buckling to the other two buckling modes (local and distortional) as shown in Fig. 2. To use this method, two quantities should be calculated first: the cross-sectional plastic resistance $\left(P_{y}=A_{g} F_{y}\right)$ and the critical elastic buckling load for the buckling mode under consideration. The column axial strength calculation equations are [2]:

- Global buckling:

$$
\lambda_{c}=\sqrt{\frac{P_{y}}{P_{c r e}}}
$$




\title{
Direct Strength Method for Calculating Distortional Buckling Capacity of Cold-Formed Thin-
}

\section{Walled Steel Columns with Uniform and Non-Uniform Elevated Temperatures}

\author{
Ashkan Shahbazian, Yong Chang Wang*
}

School of Mechanical, Aerospace and Civil Engineering, the University of Manchester, United Kingdom

*corresponding author

Email: yong.wang@manchester.ac.uk

Address: School of Mechanical, Aerospace and Civil Engineering, the University of Manchester, Pariser Building, Sackville Street, Manchester M13 9PL, United Kingdom

Tel: 00441613068968

\begin{abstract}
This paper assesses the applicability of the Direct Strength Method (DSM) to calculating the distortional buckling strength of cold-formed thin-walled (CF-TW) steel members with uniform and non-uniform elevated temperature distributions in the cross-section. The assessment was carried out by checking the DSM calculation results with numerical simulation results using the general finite element software ABAQUS which was further validated against ambient and uniform elevated temperature tests on short lipped channel sections, in addition to the author's previous validation studies for thin-walled steel columns with non-uniform temperature distributions. The validated numerical model has been used to generate an extensive database (453) of numerical results of load carrying capacity of CF-TW members with different uniform and non-uniform temperature distributions in the cross-sections, under different boundary and loading conditions and with different dimensions and lengths. It is concluded that the existing DSM distortional buckling curve for ambient temperature application is also applicable for columns with uniform temperature distributions in the cross-section, but is un-conservative for columns with non-uniform temperature distributions in the cross-section. This paper proposes a modification to the distortional buckling curve to enable DSM to deal with distortional buckling in columns with nonuniform temperature distributions.
\end{abstract}

Keywords: Steel; Cold-formed; Thin-walled; Direct Strength Method; Distortional Buckling; Fire Resistance; Numerical Modelling; Non-Uniform Elevated Temperature; Uniform Elevated Temperature; 


\section{Introduction}

The use of Cold-Formed Thin-Walled (CF-TW) steel structures in both industrial and residential constructions has grown in recent years, mainly because unusual cross-section configurations can be produced economically, in addition to their lightness and ease of fabrication. Predicting the ultimate strength of such profiles at both ambient and elevated temperatures is important for structural engineers. For predicting the load carrying capacity of CF-TW steel structural members, the effective width method is traditionally followed, but in recent years the Direct Strength Method (DSM) [1] is becoming more popular as it avoids lengthy calculations of the effective widths. This new method now has been adopted by AISI [2] for ambient temperature applications.

For CF-TW steel members exposed to fire condition from one side, using the effective width method is calculation-intensive and time-consuming because of the non-uniform distributions of mechanical properties of steel, which is a result of non-uniform temperature distributions in the cross-section. Using DSM would be particularly advantageous, especially when dealing with optimised cross-sections such as lipped channels with multiple stiffeners. For example, Figure 1 shows how the critical buckling loads of a column may be improved by using web stiffeners in the cross-section. In the conventional effective width method, the need to divide the cross-section into many plate elements makes the calculations a complex process when the mechanical properties of the plates are not uniform under non-uniform temperatures in the cross-section. In two related research papers recently published by the authors $[3,4]$, the Direct Strength Method (DSM) has been successfully applied to dealing with thin-walled steel columns with non-uniform temperature distributions in the cross-sections for global and local buckling. This paper continues this series of research and applies DSM to distortional buckling. 


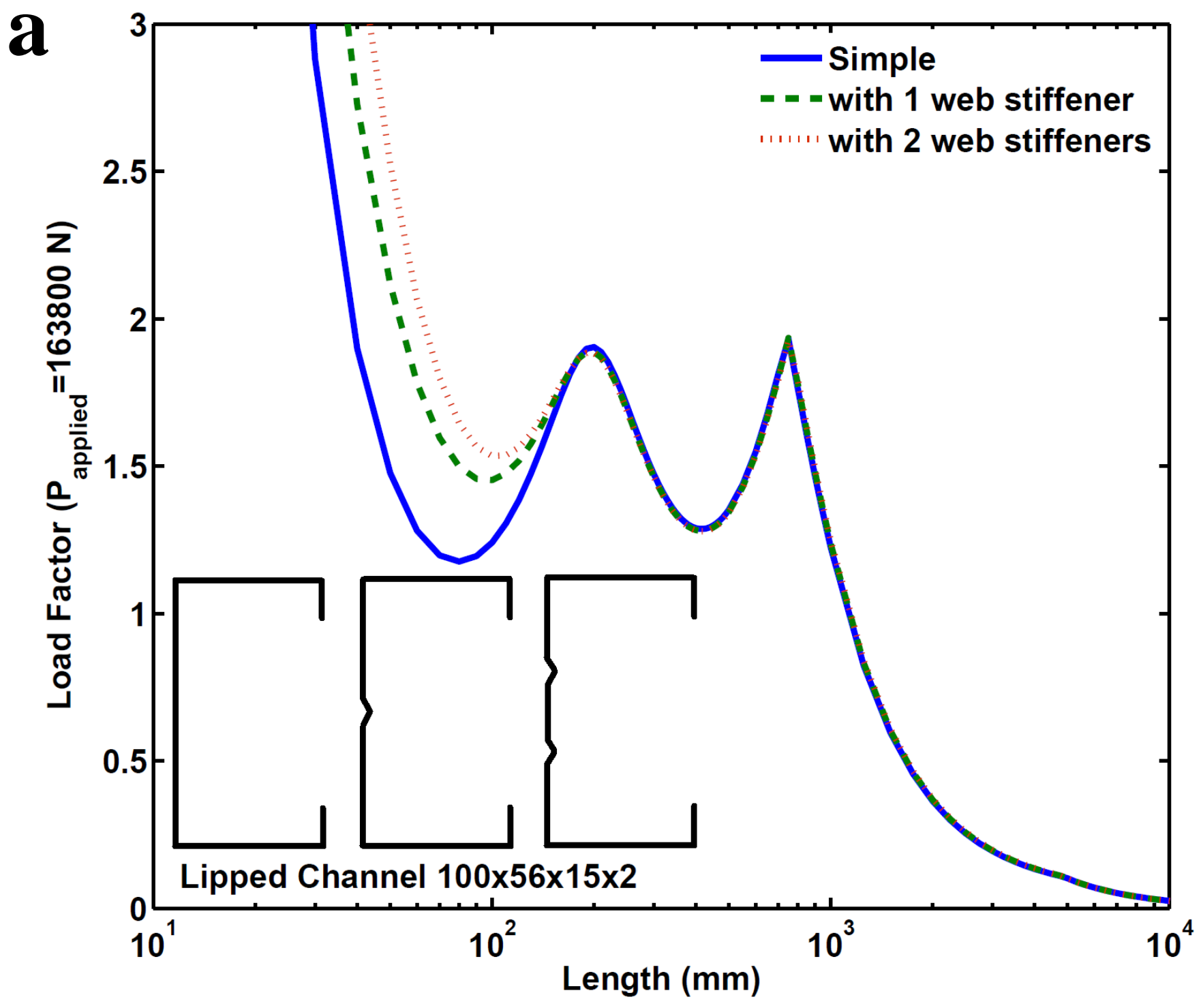




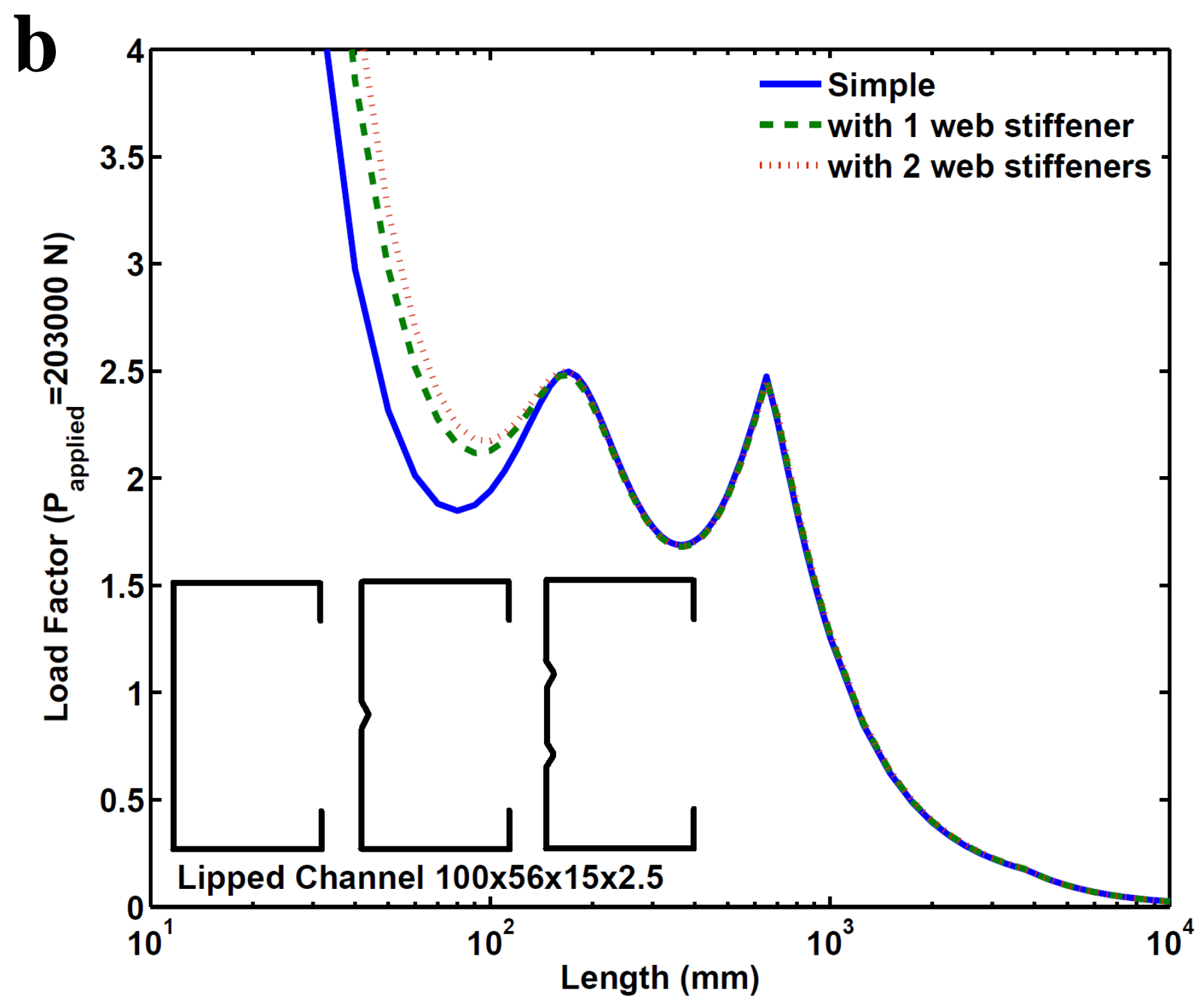

Figure 1. Effect of web stiffeners on local buckling; (a) LC100x56x15x2 and (b) LC100x56x15x2.5 
DSM is an extension of the column buckling curve for global buckling to the other two buckling modes (local and distortional) as shown in Figure 2. To use this method, two quantities should be calculated first: the cross-sectional plastic resistance $\left(\mathrm{P}_{\mathrm{y}}=\mathrm{A}_{\mathrm{g}} \mathrm{F}_{\mathrm{y}}\right)$ and the critical elastic buckling load for the buckling mode under consideration. The column axial strength calculation equations are [2]:

- Global buckling:

$$
\begin{gathered}
\lambda_{c}=\sqrt{\frac{P_{y}}{P_{\text {cre }}}} \\
\text { for } \lambda_{c} \leq 1.5, \\
\text { for } \lambda_{c}>1.5, \\
P_{n e}=\left(0.658^{\lambda_{c}{ }^{2}}\right) P_{y} \\
P_{n e}=\left(\frac{0.877}{\lambda_{c}{ }^{2}}\right) P_{y}
\end{gathered}
$$

- Distortional buckling:

$$
\begin{gathered}
\lambda_{d}=\sqrt{\frac{P_{y}}{P_{c r d}}} \\
\text { for } \lambda_{d} \leq 0.561, \\
P_{n d}=P_{y} \\
\text { for } \lambda_{d}>0.561, \quad P_{n d}=\left(1-0.25\left(\frac{P_{c r d}}{P_{y}}\right)^{0.6}\right)\left(\frac{P_{c r d}}{P_{y}}\right)^{0.6} P_{y}
\end{gathered}
$$

- Local buckling (including local - global interaction):

$$
\begin{gathered}
\lambda_{l}=\sqrt{\frac{P_{n e}}{P_{c r l}}} \\
\text { for } \lambda_{l} \leq 0.776, \\
P_{n l}=P_{n e} \\
\text { for } \lambda_{l}>0.776, \quad P_{n l}=\left(1-0.15\left(\frac{P_{c r l}}{P_{n e}}\right)^{0.4}\right)\left(\frac{P_{c r l}}{P_{n e}}\right)^{0.4} P_{n e}
\end{gathered}
$$

In the above equations: $P_{y}$ is the squash load (axial resistance) of the cross-section; $P_{c r e}$ is the critical elastic global buckling load; $P_{c r d}$ is the critical elastic distortional buckling load; $P_{c r l}$ is the critical elastic local buckling load; $\lambda_{c}, \lambda_{d}$ and $\lambda_{l}$ are the slenderness for global, distortional and local buckling modes respectively; $P_{n e}, P_{n l}$ and $P_{n d}$ are the column axial strength for global, distortional and local buckling modes respectively.

The axial strength of the column is the minimum of $P_{n e}, P_{n l}$ and $P_{n d}$. 


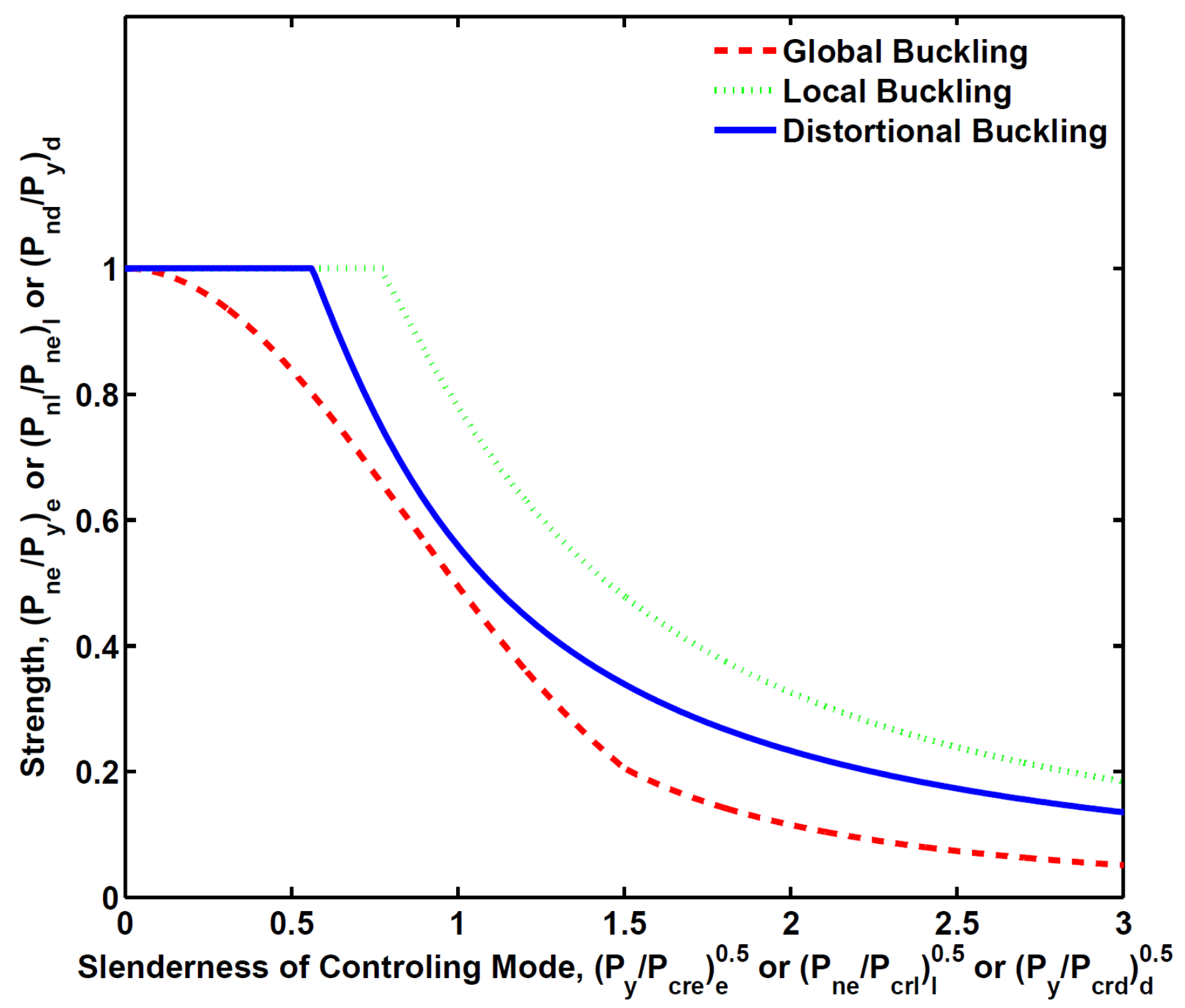

Figure 2. DSM buckling curves for ambient temperature

A large number of research studies have been carried out to develop this method for thin-walled columns at ambient temperature, and an extensive review of the development has been provided by Schafer [5]. Developments are also underway to extend this method to steel columns with holes [6-8].

This paper attempts to extend DSM to thin-walled steel columns with non-uniform temperature distributions in the cross-section under fire exposure. The general area of fire resistance of thin-walled structures has attracted only a small number of research studies. Among them, most of the research studies are concerned with uniform temperature distribution (Feng et al. [9-12], Kaitila [13, 14], Heva et al. [15], Ranawaka and Mahendran [16, 17]) or mechanical properties (e.g. Chen and Young [18-20]). Within these existing research studies, Ranawaka and Mahendran [16, 17] performed a preliminary study to exploit the applicability of DSM to distortional buckling with uniform temperature distribution in the column cross-section. They compared the DSM distortional buckling results with both numerical and 
experimental results and concluded that in many cases the DSM distortional buckling curve would give un-conservative results but in some cases the results were conservative.

In practical applications, CF-TW steel members are protected by gypsum boards (plaster) and this result in non-uniform temperature distributions in the cross-sections. The investigations of Feng et al. [10, 2123 ] represent the most thorough study in this field. They carried out elevated temperature and fire tests on CF-TW steel members in panels, and numerical and analytical studies to quantify heat transfer and load carrying capacities. Their experimental studies on panels (non-uniform temperatures) have been used to validate the authors' numerical model [3]. This research will further use their experiments on short CFTW columns $[11,12]$ that failed in distortional buckling mode to validate the author's numerical model for this buckling mode (see section 2 for details) and their heat transfer results $[10,21]$ will be adopted in this study to determine the assumed non-uniform temperature distributions in the cross-sections.

The two recent publications by the authors $[3,4]$ appear to be the only ones applying DSM to thin-walled columns with non-uniform temperature distributions in the cross-sections. These studies investigated global and local buckling respectively. In these publications modified global and local buckling curves were proposed for non-uniform temperature applications. The modified equations are:

- Global buckling for steel columns with non-uniform temperature distributions in the crosssections:

$$
\begin{array}{ll}
\text { for } \lambda_{c} \leq 1.5, & P_{n e}=\left(0.495^{\lambda^{2}}\right) P_{y} \\
\text { for } \lambda_{c}>1.5, & P_{n e}=\left(\frac{0.462}{\lambda_{c}{ }^{2}}\right) P_{y}
\end{array}
$$

- Local buckling (including local - global interaction) for steel columns with non-uniform temperature distributions in the cross-sections:

$$
\begin{aligned}
& \text { for } \lambda_{l} \leq 0.776, \quad P_{n l}=P_{n e} \\
& \text { for } \lambda_{l}>0.776 \text {, } \\
& P_{n l}=\left(1-0.22\left(\frac{P_{c r l}}{P_{n e}}\right)^{0.75}\right)\left(\frac{P_{c r l}}{P_{n e}}\right)^{0.75} P_{n e}
\end{aligned}
$$

Equations 4 and 5 should replace equations 1 and 3 respectively. The aim of this research is to assess the applicability of equation 2 to steel columns under distortional buckling with non-uniform temperature distributions in the column cross-sections and if necessary, to find a revised equation. 


\section{Validation of FE modelling against experimental study}

Feng et al. [12] carried out 52 steady state tests on lipped and un-lipped channel sections at ambient and uniform elevated temperatures. To validate the authors' ABAQUS simulation model, five of the tests on lipped channel (100x56x15x2), which experienced distortional buckling, were simulated. These tests were performed on columns of $400 \mathrm{~mm}$ in length and tested at five temperature levels: ambient, $250^{\circ} \mathrm{C}$, $400^{\circ} \mathrm{C}, 550^{\circ} \mathrm{C}$ and $700^{\circ} \mathrm{C}$. Feng et al. [11] also carried out numerical modelling of their tests using ABAQUS. They used the mechanical properties in Table 1 which were based on their tensile coupon tests at ambient temperature. They then applied the elevated temperature mechanical model in EN1993-1-2 [24] to obtain the elevated temperature stress-strain curves.

These tests have been simulated using the general finite element package ABAQUS [25]. Based on the authors' pervious ABAQUS simulation models [3, 4], shell element type $\mathrm{S} 4$ with mesh size $5 \mathrm{~mm}$ was found to be suitable. Table 1 lists the mechanical properties of the steel at different temperatures, based on the coupon tests [12] at ambient temperature and elevated temperature strength and stiffness reduction factors in EN1993-1-2 [24].

The simulation results were expected to be different depending on the mode and scale of initial imperfection. Tables 2 and 3, and Figures 3 and 4 present the results of sensitivity study for initial imperfection (15 different combinations of imperfection scale and shape for an ambient temperature test, 5 different combinations for each of the 4 elevated temperature tests). The simulation results for column strength are close to the test results and are not particularly sensitive to the different combinations of initial imperfection. It is acceptable to use an initial imperfection scale of 50\%t under distortional buckling (model 4).

Table 1. Mechanical properties based on tensile coupon tests at ambient temperature [12] and EN 1993-1-2 [24] reduction factors at elevated temperatures

\begin{tabular}{|c|c|c|c|c|}
\hline $\begin{array}{c}\text { Temperature } \\
\left({ }^{\circ} \mathrm{C}\right)\end{array}$ & $\begin{array}{l}\text { Yield Stress } \\
\left(\mathrm{N} / \mathrm{mm}^{2}\right)\end{array}$ & $\begin{array}{l}\text { Ultimate Stress } \\
\left(\mathrm{N} / \mathrm{mm}^{2}\right)\end{array}$ & $\begin{array}{l}\text { Elastic Modulus } \\
\quad\left(\mathrm{N} / \mathrm{mm}^{2}\right)\end{array}$ & Reference \\
\hline $20-100$ & 406.00 & 494.59 & 189650.00 & Coupon test [12] \\
\hline 250 & 339.01 & \multirow{4}{*}{$\begin{array}{l}\text { no strain } \\
\text { hardening }\end{array}$} & 161202.50 & \multirow{4}{*}{ EN1993-1-2 [24] } \\
\hline 400 & 263.90 & & 132755.00 & \\
\hline 550 & 168.49 & & 86290.75 & \\
\hline 700 & 52.78 & & 24654.50 & \\
\hline
\end{tabular}


Table 2. Sensitivity study results for initial imperfection at ambient temperature

\begin{tabular}{ccc|ccc}
\hline \multirow{2}{*}{ Model \# } & \multicolumn{2}{c|}{ Imperfection shape and Scale } & \multicolumn{3}{c}{ Failure Load (kN) } \\
\cline { 2 - 6 } & Local buckling & Distortional buckling & This research & Feng's et al. Simulation [11] & Feng's et al test [12] \\
\hline 1 & $50 \% \mathrm{t}$ & - & 134.56 & - & - \\
2 & $100 \% \mathrm{t}$ & - & 124.07 & 125.30 & - \\
3 & $150 \% \mathrm{t}$ & - & 116.69 & - & - \\
4 & - & $50 \% \mathrm{t}$ & $\mathbf{1 4 7 . 4 7}$ & - & - \\
5 & - & $100 \% \mathrm{t}$ & 140.76 & - & - \\
6 & - & $150 \% \mathrm{t}$ & 130.20 & - & - \\
7 & $50 \% \mathrm{t}$ & 138.43 & - & - \\
8 & $50 \% \mathrm{t}$ & $100 \% \mathrm{t}$ & - & - \\
9 & $50 \% \mathrm{t}$ & $150 \% \mathrm{t}$ & 143.40 & - & - \\
10 & $100 \% \mathrm{t}$ & $50 \% \mathrm{t}$ & 126.76 & - & - \\
11 & $100 \% \mathrm{t}$ & 129.29 & - & - \\
12 & $100 \% \mathrm{t}$ & 131.65 & - & - \\
13 & $150 \% \mathrm{t}$ & $150 \% \mathrm{t}$ & 118.79 & - & -
\end{tabular}

Table 3. Sensitivity study results for initial imperfection at elevated temperatures

\begin{tabular}{|c|c|c|c|c|c|c|}
\hline \multirow{2}{*}{$\begin{array}{l}\text { Temperature } \\
\left({ }^{\circ} \mathrm{C}\right)\end{array}$} & \multirow{2}{*}{$\begin{array}{c}\text { Model } \\
\#\end{array}$} & \multicolumn{2}{|c|}{ Imperfection shape and Scale } & \multicolumn{3}{|c|}{ Failure Load $(\mathrm{kN})$} \\
\hline & & $\begin{array}{c}\text { Local } \\
\text { buckling }\end{array}$ & $\begin{array}{l}\text { Distortional } \\
\text { buckling }\end{array}$ & $\begin{array}{l}\text { This } \\
\text { research }\end{array}$ & $\begin{array}{c}\text { Feng's et al. Simulation } \\
\text { [11] }\end{array}$ & $\begin{array}{c}\text { Feng's et al test } \\
{[12]}\end{array}$ \\
\hline \multirow{5}{*}{250} & 2 & $100 \% \mathrm{t}$ & - & 104.41 & 109.80 & 123.69 \\
\hline & 4 & - & $50 \% \mathrm{t}$ & 122.47 & - & - \\
\hline & 5 & - & $100 \% \mathrm{t}$ & 112.11 & - & - \\
\hline & 11 & $100 \% \mathrm{t}$ & $100 \% \mathrm{t}$ & 107.25 & - & - \\
\hline & 12 & $100 \% \mathrm{t}$ & $150 \% \mathrm{t}$ & 107.19 & - & - \\
\hline \multirow{5}{*}{400} & 2 & $100 \% \mathrm{t}$ & - & 78.52 & 87.18 & 101.87 \\
\hline & 4 & - & $50 \% \mathrm{t}$ & 90.45 & - & - \\
\hline & 5 & - & $100 \% \mathrm{t}$ & 83.24 & - & - \\
\hline & 11 & $100 \% \mathrm{t}$ & $100 \% \mathrm{t}$ & 81.42 & - & - \\
\hline & 12 & $100 \% \mathrm{t}$ & $150 \% \mathrm{t}$ & 81.95 & - & - \\
\hline \multirow{5}{*}{550} & 2 & $100 \% \mathrm{t}$ & - & 50.96 & 55.92 & 45.52 \\
\hline & 4 & - & $50 \% \mathrm{t}$ & 59.65 & - & - \\
\hline & 5 & - & $100 \% \mathrm{t}$ & 54.98 & - & - \\
\hline & 11 & $100 \% \mathrm{t}$ & $100 \% \mathrm{t}$ & 52.86 & - & - \\
\hline & 12 & $100 \% \mathrm{t}$ & $150 \% \mathrm{t}$ & 53.54 & - & - \\
\hline \multirow{5}{*}{700} & 2 & $100 \% \mathrm{t}$ & - & 15.49 & 17.68 & 15.77 \\
\hline & 4 & - & $50 \% \mathrm{t}$ & 17.52 & - & - \\
\hline & 5 & - & $100 \% \mathrm{t}$ & 16.13 & - & - \\
\hline & 11 & $100 \% \mathrm{t}$ & $100 \% \mathrm{t}$ & 16.19 & - & - \\
\hline & 12 & $100 \% \mathrm{t}$ & $150 \% \mathrm{t}$ & 16.29 & - & - \\
\hline
\end{tabular}



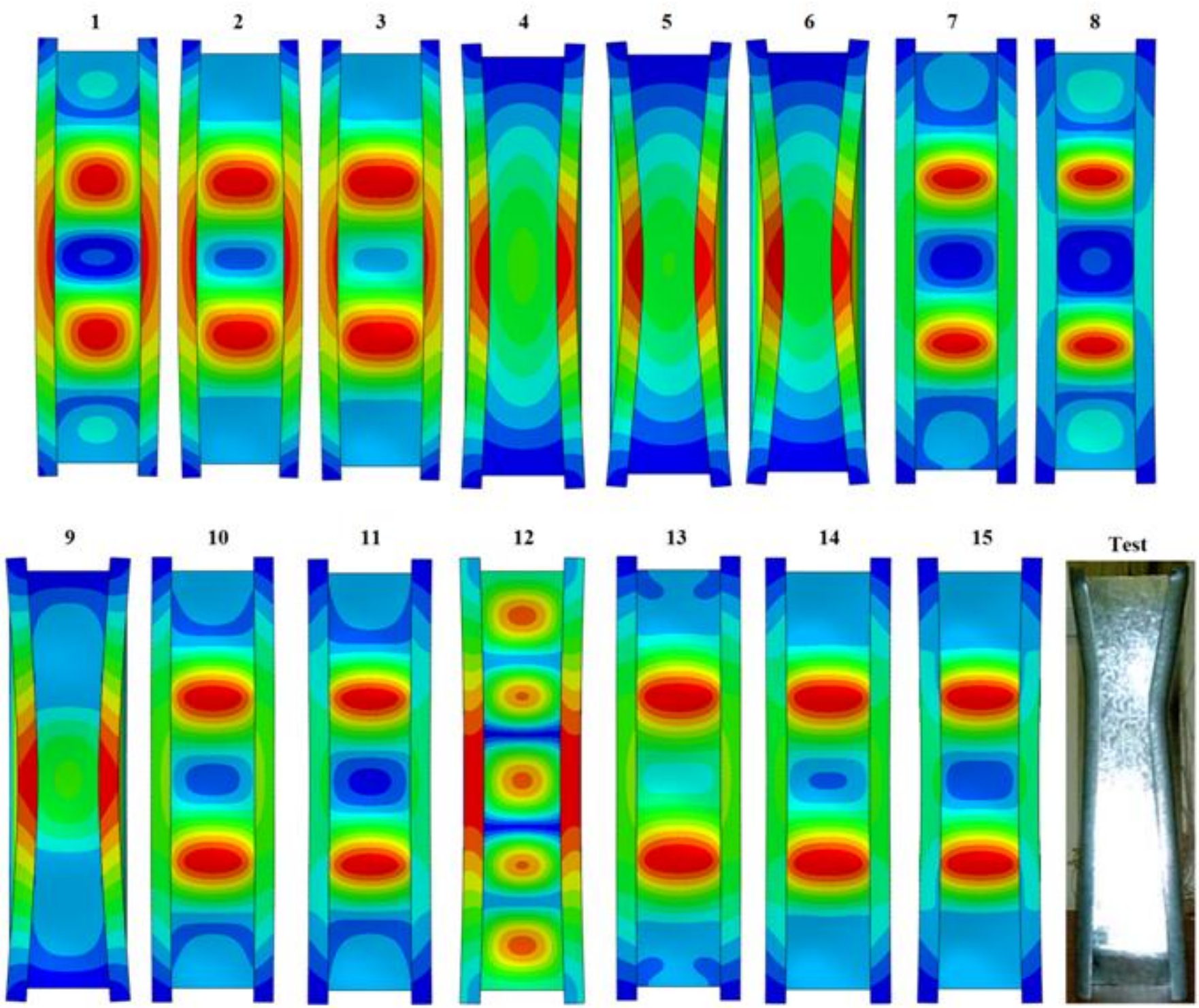

Figure 3. Comparison of deformed shapes between simulations with different imperfections and experiment [12] at ambient temperature 

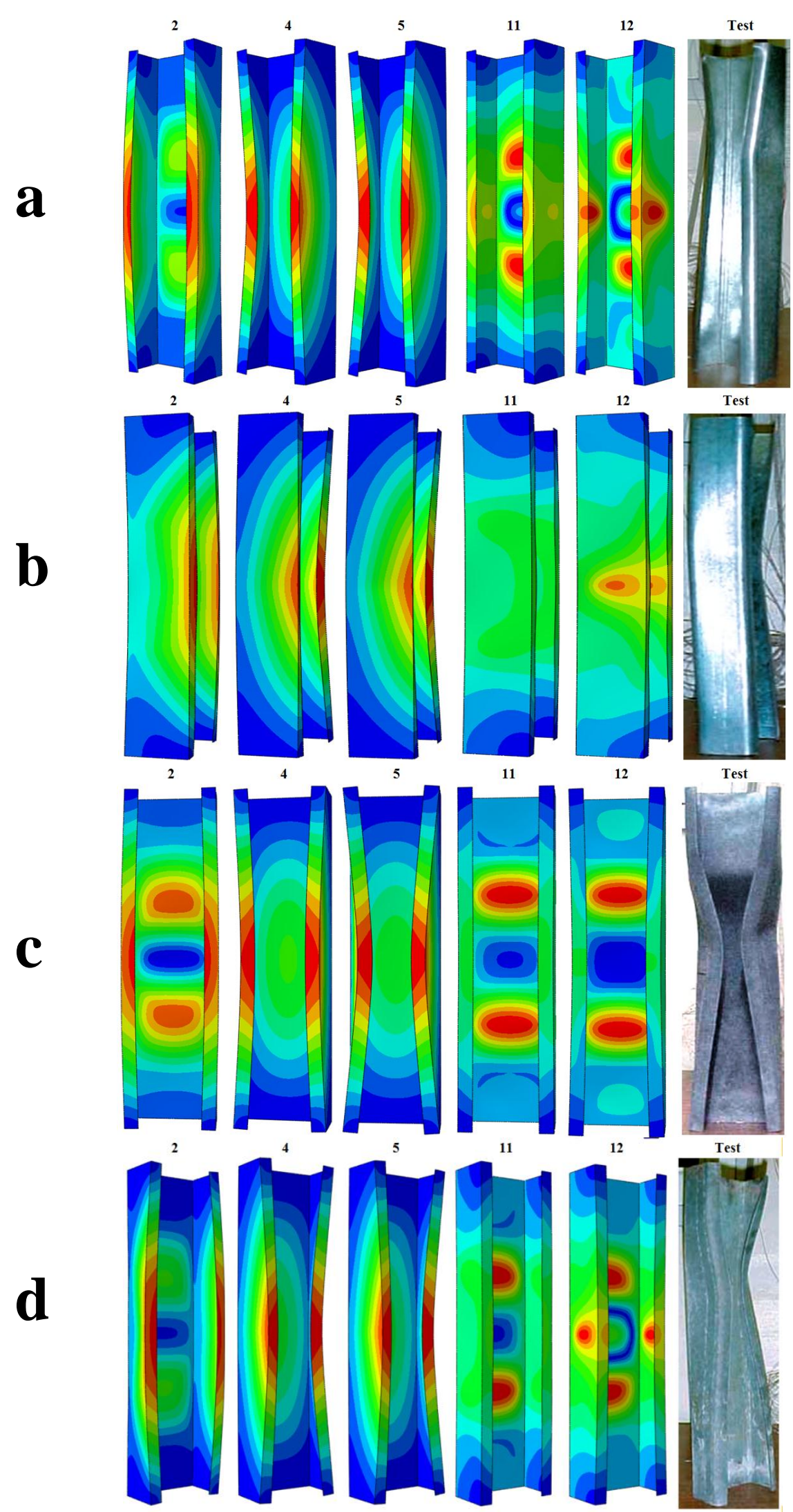

Figure 4. Comparison of deformed shapes between simulations with different imperfections and experiment [12] at uniform elevated temperature of; (a) $250{ }^{\circ} \mathrm{C}$, (b) $400{ }^{\circ} \mathrm{C}$, (c) $550{ }^{\circ} \mathrm{C}$ and (d) $700{ }^{\circ} \mathrm{C}$ 


\section{Numerical parametric studies for ultimate strength at elevated temperatures}

In order to generate a database of results to assess the DSM distortional buckling curve for elevated temperature applications, an extensive parametric study has been performed using the validated ABAQUS model for distortional buckling with uniform temperature and non-uniform temperature distributions in the cross-sections.

The ambient temperature steel yield stress was taken as either 350,450 or $550 \mathrm{~N} / \mathrm{mm}^{2}$ and the elastic modulus as $205000 \mathrm{~N} / \mathrm{mm}^{2}$. The different steel yield stresses were used in order to give different values of distortional buckling slenderness. The elevated temperature stress-strain relationships were derived based on Eurocode EN 1993-1-2 [24] and Figure 5 shows an example for $450 \mathrm{~N} / \mathrm{mm}^{2}$. A constant thermal expansion coefficient of $0.000014 /{ }^{\circ} \mathrm{C}$ was assumed.



Figure 5. Stress-strain relationship of steel at different temperatures based on Eurocode EN 1993-1-2 [24] 
Three sets of parametric studies were performed: at ambient temperature to check the basic equations of DSM for distortional buckling and to further validate the FE models; at uniform elevated temperatures to check applicability of the existing DSM equations for members with uniform temperature distribution in the cross-section; and with non-uniform temperature distributions in the cross-section.

Figure 6 shows the assumed non-uniform temperature distribution. The temperature distribution for each flange and connected lip was assumed to be uniform while the temperature distribution in the web was linear. This assumed temperature distribution was found by Feng et al. [22] and the authors [3] to be appropriate for the purpose of calculating the strength of thin-walled studs in wall panels.

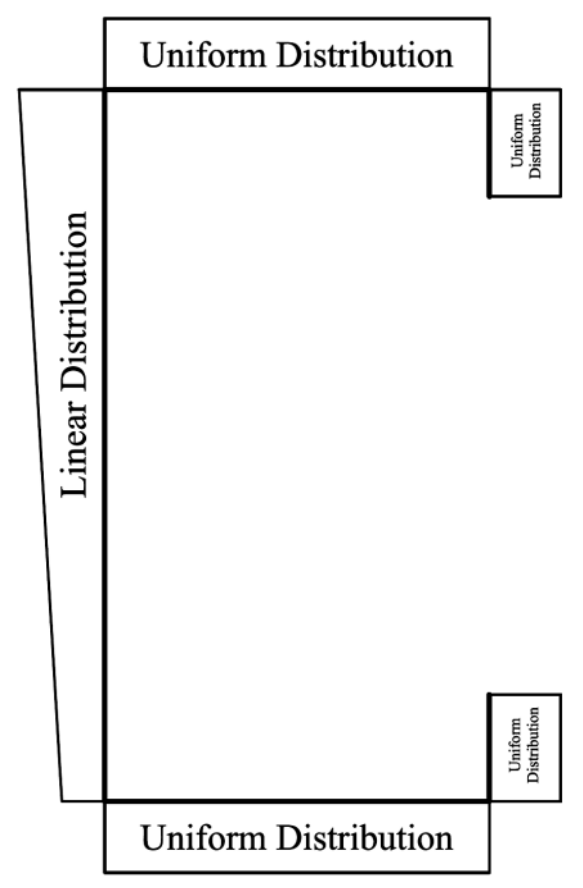

Figure 6. Assumed temperature distiburtion in the cross-section $[3,22]$

Boundary conditions at column ends were assumed to be simply supported (Figure 7). To simulate connections to gypsum boards within the length, column (long ones) restrained from horizontal movements at $300 \mathrm{~mm}$ intervals along the centre line of the flanges. 

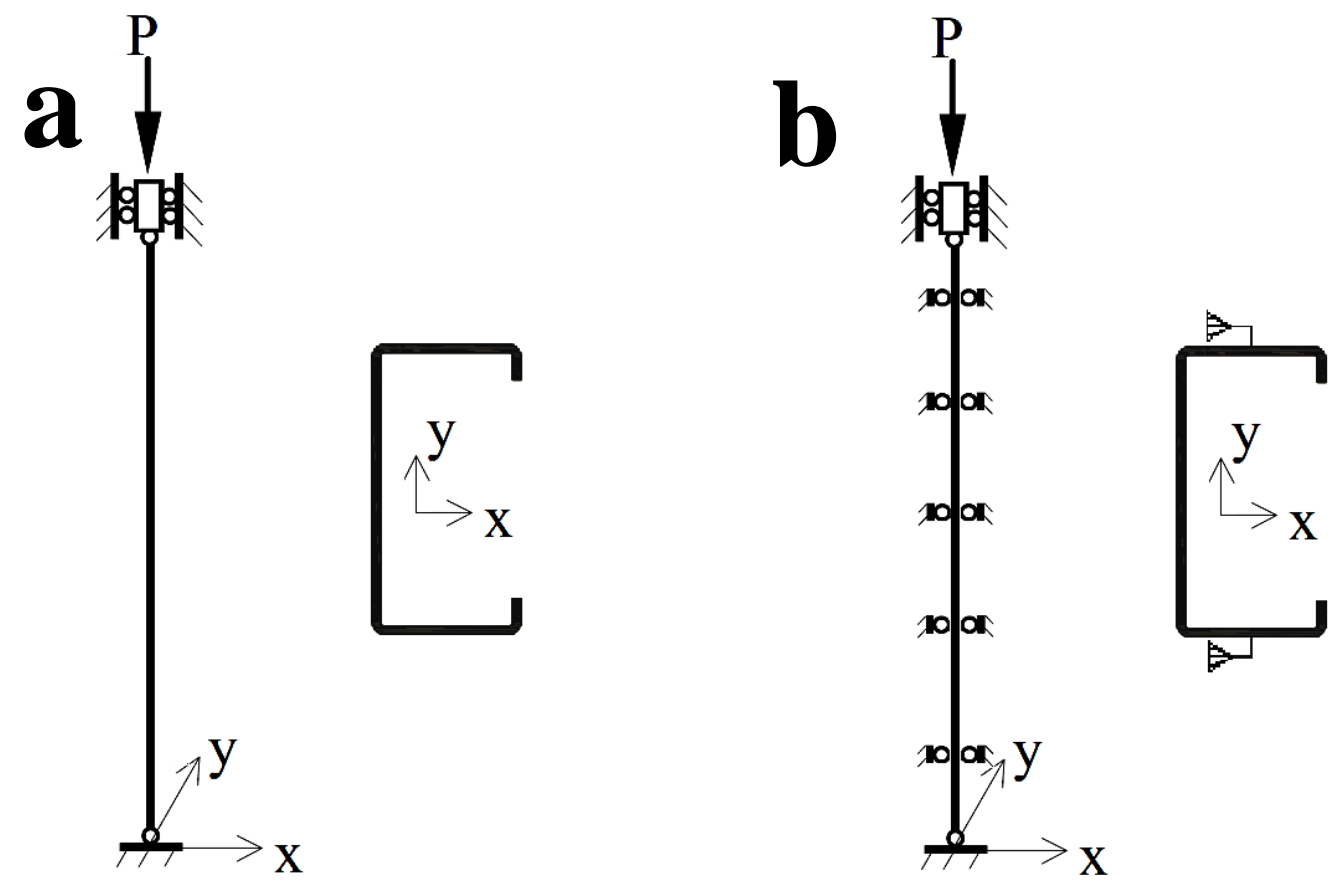

Figure 7. Boundary conditions and loading; (a) unrestrained in length and (b) restrained in length

For ambient and uniform elevated temperature cases, the Riks method was used. However, for the nonuniform temperature distribution case, the transient state analysis had to be adopted by applying the mechanical load to reach the desired level then increasing the temperatures while maintaining the applied load. This made it impossible to use the Riks method. Instead, the General method in ABAQUS was used.

The numerical parametric studies were performed to investigate the effects of varying the following design parameters: cross-section shapes (simple lipped channel, lipped channel with one web stiffener and lipped channel with two web stiffeners, Figure 8), cross-section thickness ( 2 or $2.5 \mathrm{~mm}$ to avoid local buckling), column length (to ensure different number of distortional buckling half-waves), temperature profiles (to simulate different possible temperature distributions), load levels and intermediate support conditions (to avoid global buckling). Three different non-uniform temperature distributions were considered, the lower temperature being $1 / 3,1 / 2$ or $2 / 3$ of the higher temperature respectively. Table 4 lists the ranges of section dimensions, boundary conditions and column lengths. 


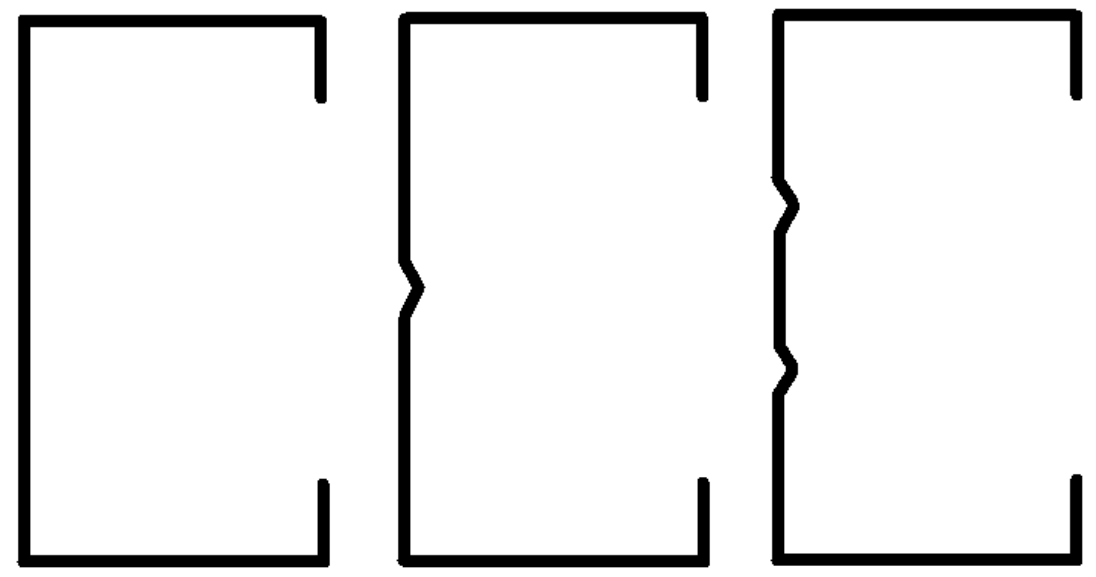

Figure 8. Cross-section shapes considered in numerical parametric study

Table 4. Cross-section dimensions for numerical study

\begin{tabular}{ccc}
\hline web $\times$ flange $\times$ lip $\times$ thickness $(\mathrm{mm})$ & $\begin{array}{c}\text { Support Condition } \\
\text { within Length }\end{array}$ & Length $(\mathrm{mm})$ \\
\hline $300 \times 45 \times 13 \times 2.5$ & unrestrained & 600 \\
$300 \times 45 \times 13 \times 2.5$ & restrained & 3000 \\
$250 \times 45 \times 13 \times 2.5$ & unrestrained & 600 \\
$250 \times 45 \times 13 \times 2.5$ & restrained & 3000 \\
$200 \times 45 \times 13 \times 2.5$ & unrestrained & 600 \\
$200 \times 45 \times 13 \times 2.5$ & restrained & 3000 \\
$150 \times 45 \times 13 \times 2.5$ & unrestrained & 600 \\
$150 \times 45 \times 13 \times 2.5$ & restrained & 3000 \\
$100 \times 56 \times 15 \times 2.5$ & unrestrained & 300 \\
$100 \times 56 \times 15 \times 2.5-1$ web stiffener & restrained & 1000 \\
$100 \times 56 \times 15 \times 2-1$ web stiffener & unrestrained & 400 \\
$100 \times 56 \times 15 \times 2-2$ web stiffeners & unrestrained & 700
\end{tabular}

In total, 42 simulations were performed at ambient temperature; 273 with uniform elevated temperature in the cross-section, with the temperature varying from $200^{\circ} \mathrm{C}$ to $800^{\circ} \mathrm{C}$; For non-uniform temperature distributions, a total of 138 simulations were performed, covering four different load ratios (from $30 \%$ to $60 \%$ ). These 138 simulations were selected to give different distortional buckling slenderness to check the distortional buckling curve. 


\section{Assessment of the Direct Strength Method}

\subsection{Ambient temperature}

The critical elastic buckling loads were calculated by using the freely available elastic eigenvalue analysis software CUFSM [26]. The column squash load was obtained by multiplying the gross cross-sectional area of the column by the yield stress of the steel.

Figure 9 compares the FE simulations with DSM calculation results for the ambient temperature cases. Included in the figures are also the experimental result of Feng et al. [12]. As expected, the DSM and FE results are in good agreement with an average difference of 6.86\%. The comparison in Figure 9 indicates that the DSM results are conservative for columns with a distortional slenderness greater than 1.5. This is in agreement with the numerical study results of Moen and Schafer [6] for lipped channels (no holes), which are also included in Figure 9. 


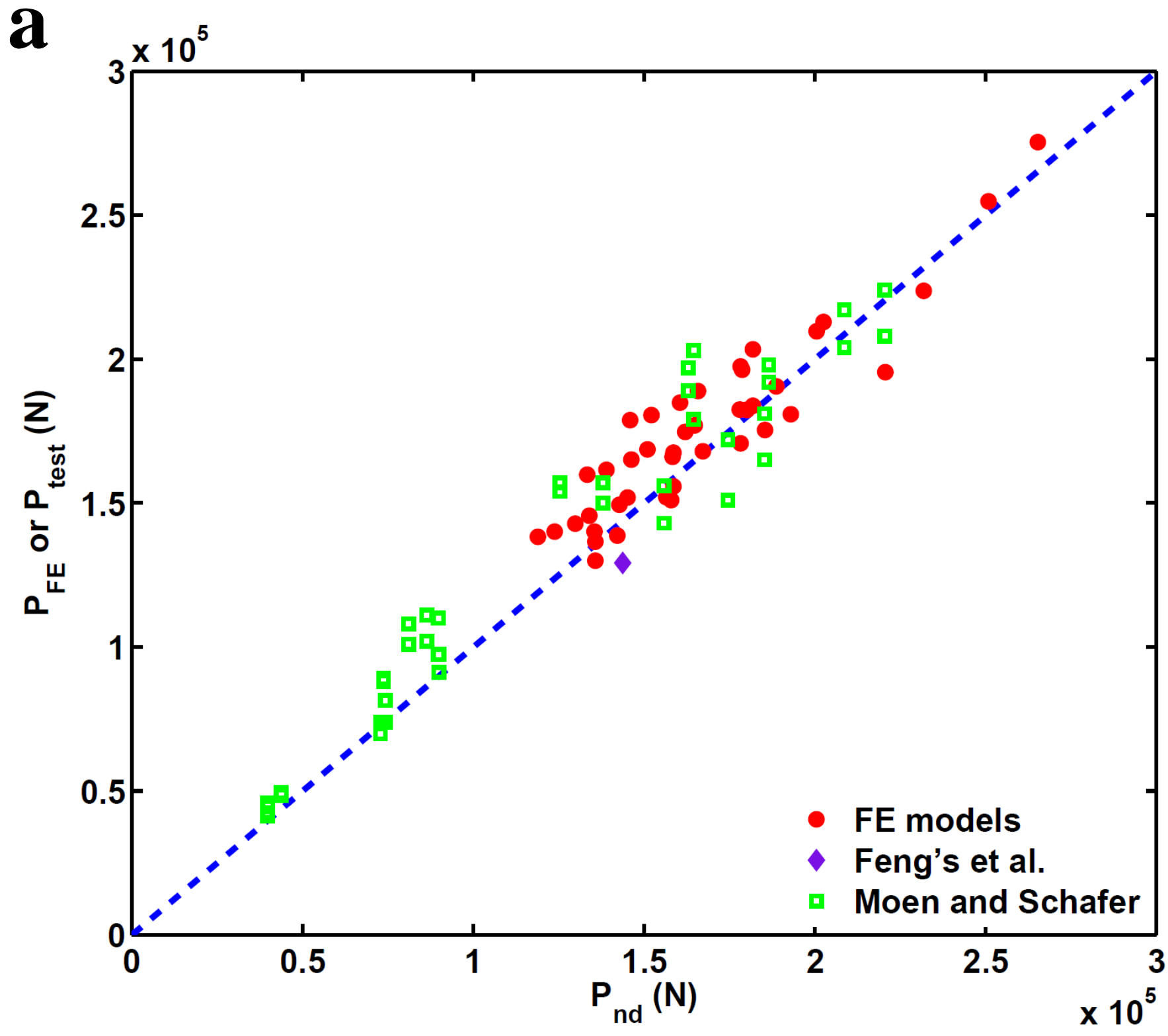




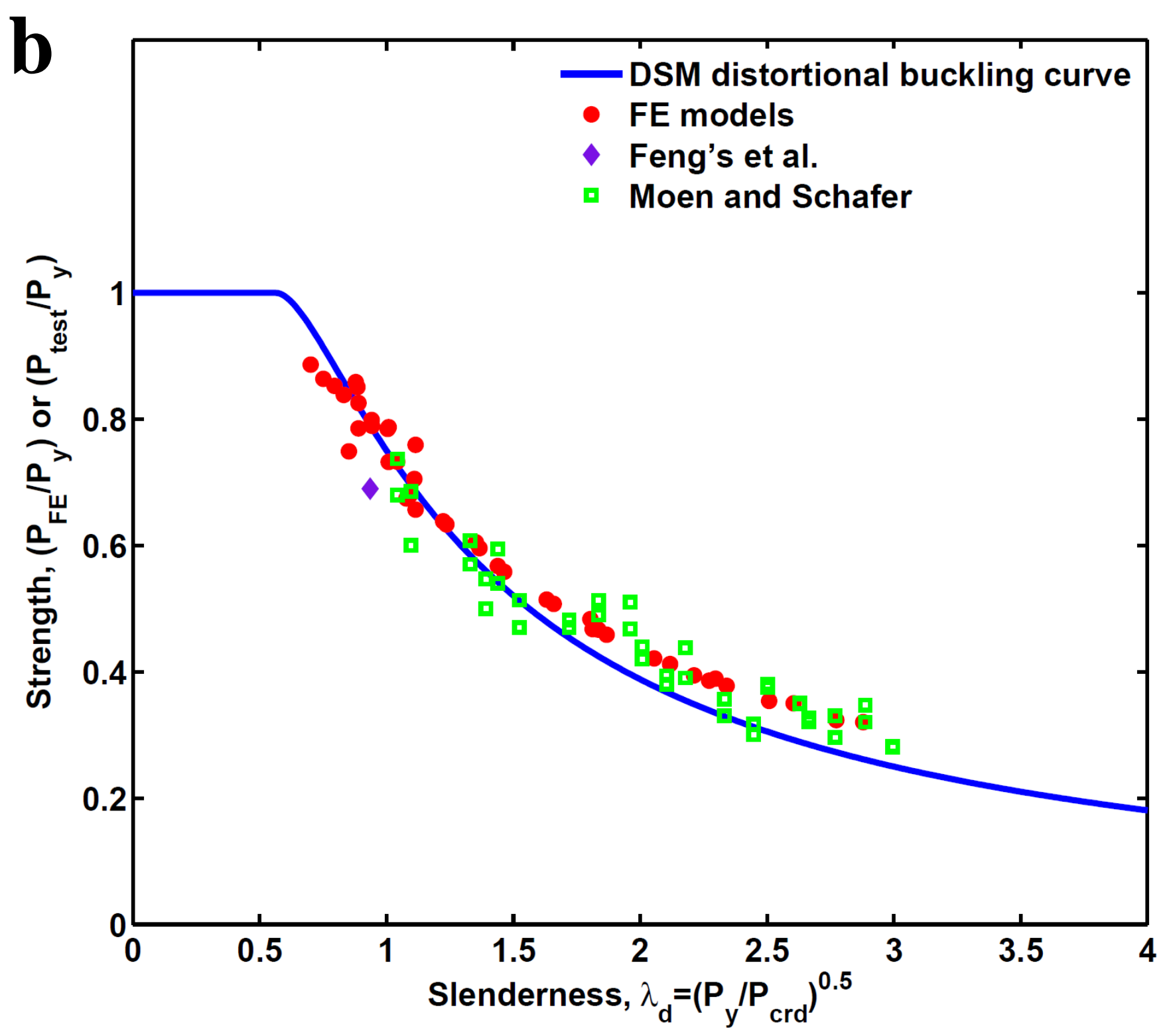

Figure 9. Comparison between results of this research and those of Moen and Schafer [6]; (a) column load-carrying capacity and (b) column load-carrying capacity - slenderness relationship. 


\subsection{Uniform elevated temperatures}

For columns with uniform elevated temperatures, the same procedure as at ambient temperature can be followed: the critical elastic buckling loads of the columns were calculated by using CUFSM [26] and the column squash loads were obtained by multiplying the gross cross-sectional areas of the columns by the yield stress of the steel at the specified temperature. The results of a recent study by the authors [4] show that the actual shape of the stress-strain relationship of steel has only minor effect on the column resistance. Therefore, even though the steel stress-strain relationship becomes curved at elevated temperature, the elastic buckling load of the column can still be calculated using the initial elastic modulus of steel at the elevated temperature. Figure 10 shows the changes in the elastic buckling load of a column at different temperatures, reflecting the reductions in the elastic modulus of steel at these different temperatures given in EN1993-1-2.

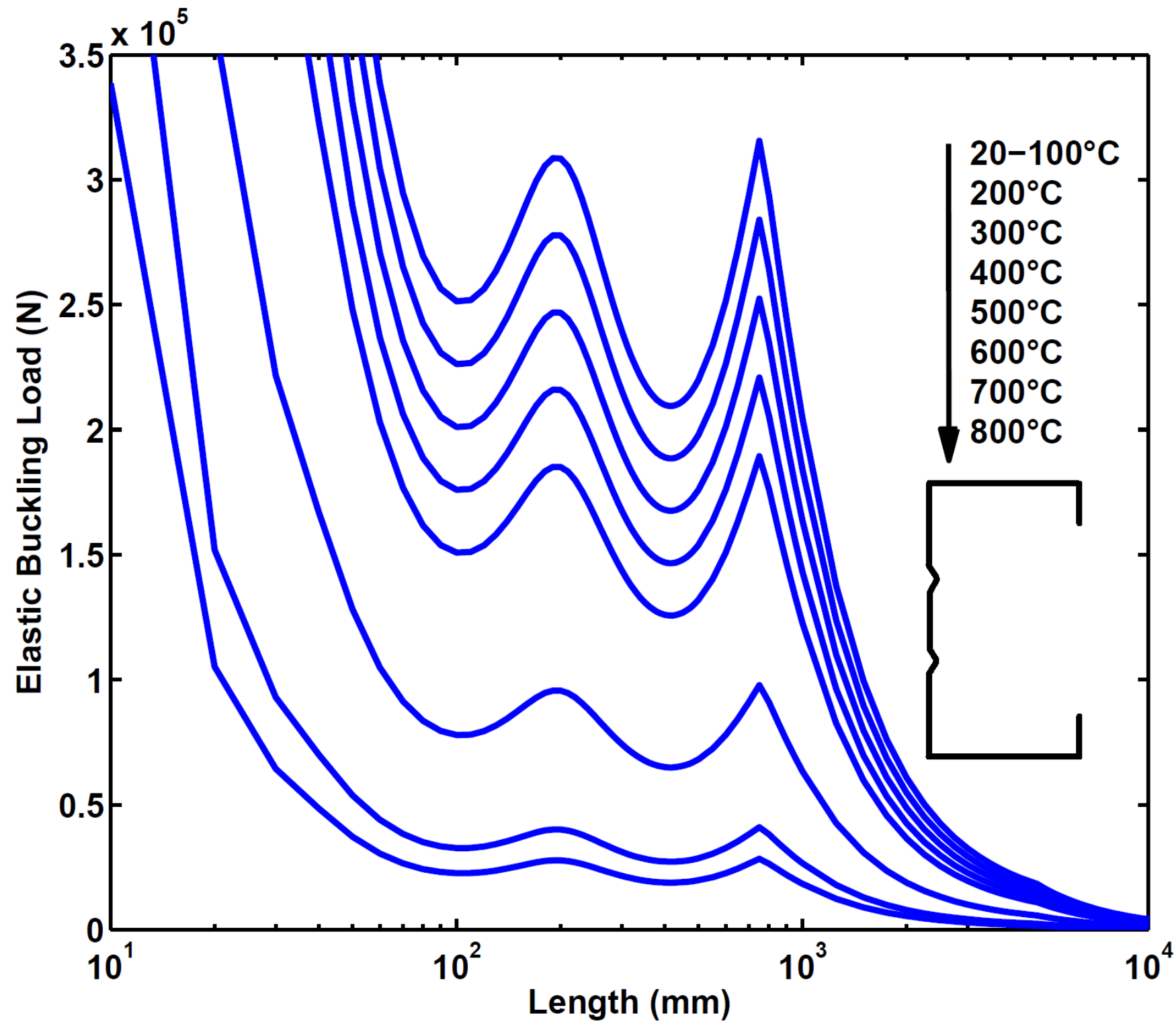


Figures 11 compares the FE simulation results with DSM calculation results for uniform elevated temperatures, included the experimental results of Feng et al. [12].

The comparison in Figure 11(b) suggests that the DSM calculation results are conservative when column distortional slenderness is greater than 1.5 , but slightly un-conservative when the slenderness is less than 1.5. This is in agreement with the conclusions of Ranawaka and Mahendran [17], who compared their experimental results with DSM calculation results. Although Figure 11 shows that the DSM calculation results are already quite close to the FE simulation results (average difference 6.84\%), the accuracy of the DSM calculation results can be improved by slightly changing the distortional buckling curve. The authors propose the following equations for members with uniform elevated temperature:

$$
\begin{array}{cc}
\text { for } \lambda_{d} \leq 0.5171, & P_{n d}=P_{y} \\
\text { for } \lambda_{d}>0.5171, & P_{n d}=0.9\left(1-0.22\left(\frac{P_{c r d}}{P_{y}}\right)^{0.5}\right)\left(\frac{P_{c r d}}{P_{y}}\right)^{0.5} P_{y}
\end{array}
$$

Figure 12 compares the FE simulation results with the DSM calculation results using the modified distortional buckling curve (equation 6). The average difference between the two sets of results is now only $3.21 \%$. 


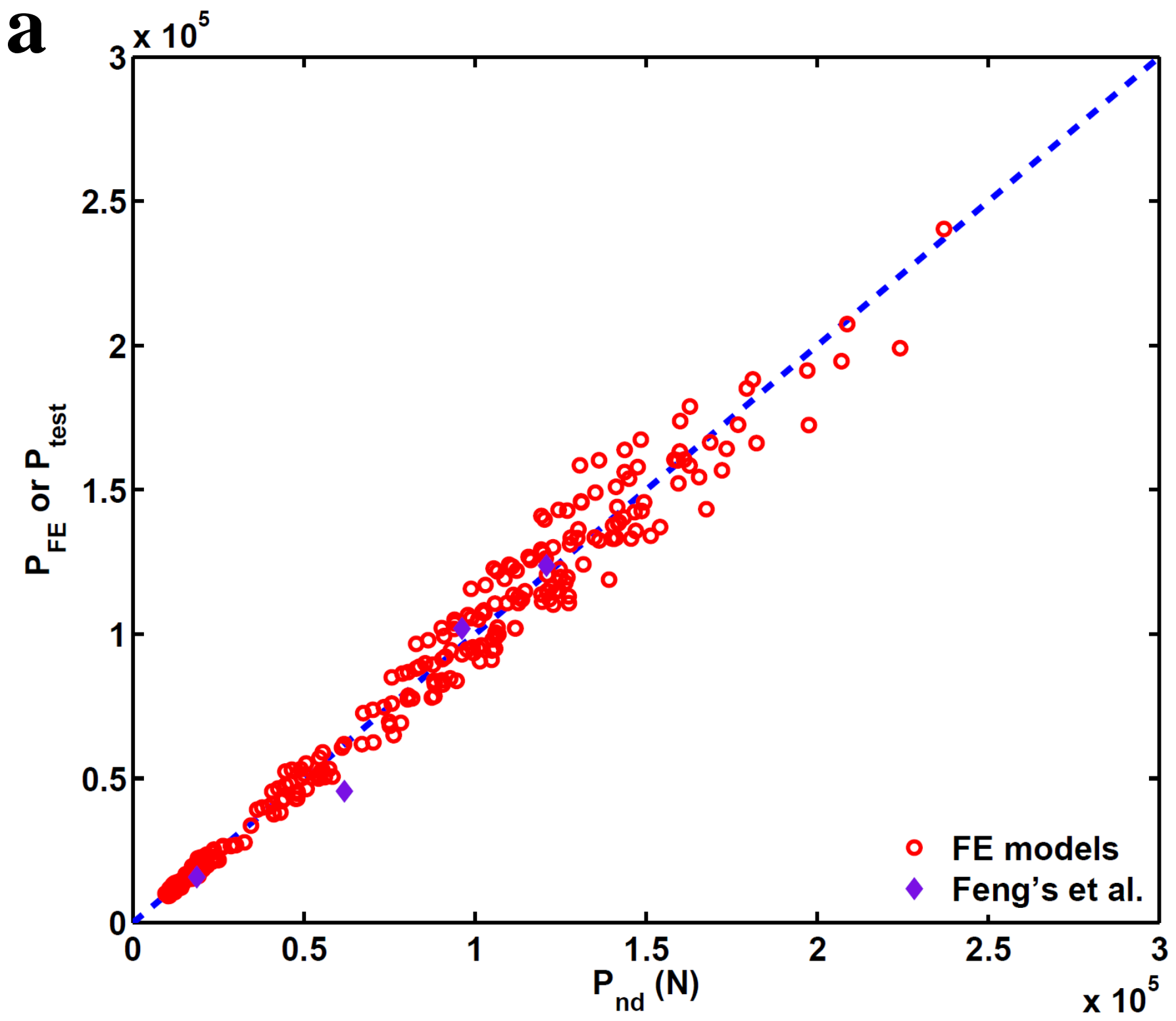




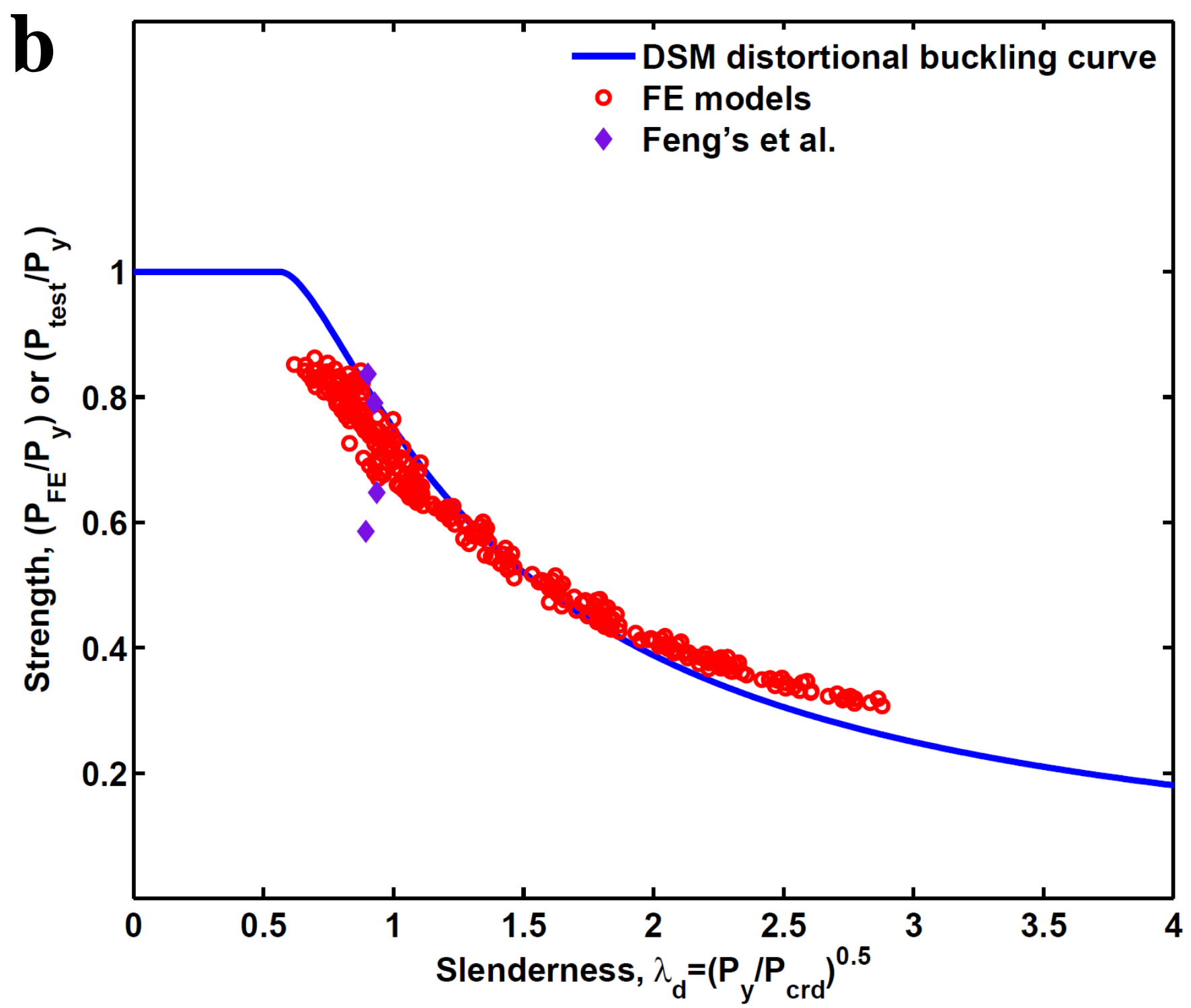

Figure 11. Comparing DSM calculation results with FE Simulations of this study and results of Fengs et al. [12] for uniform elevated temperature; (a) column load-carrying capacity and (b) column load-carrying capacity - slenderness relationship 


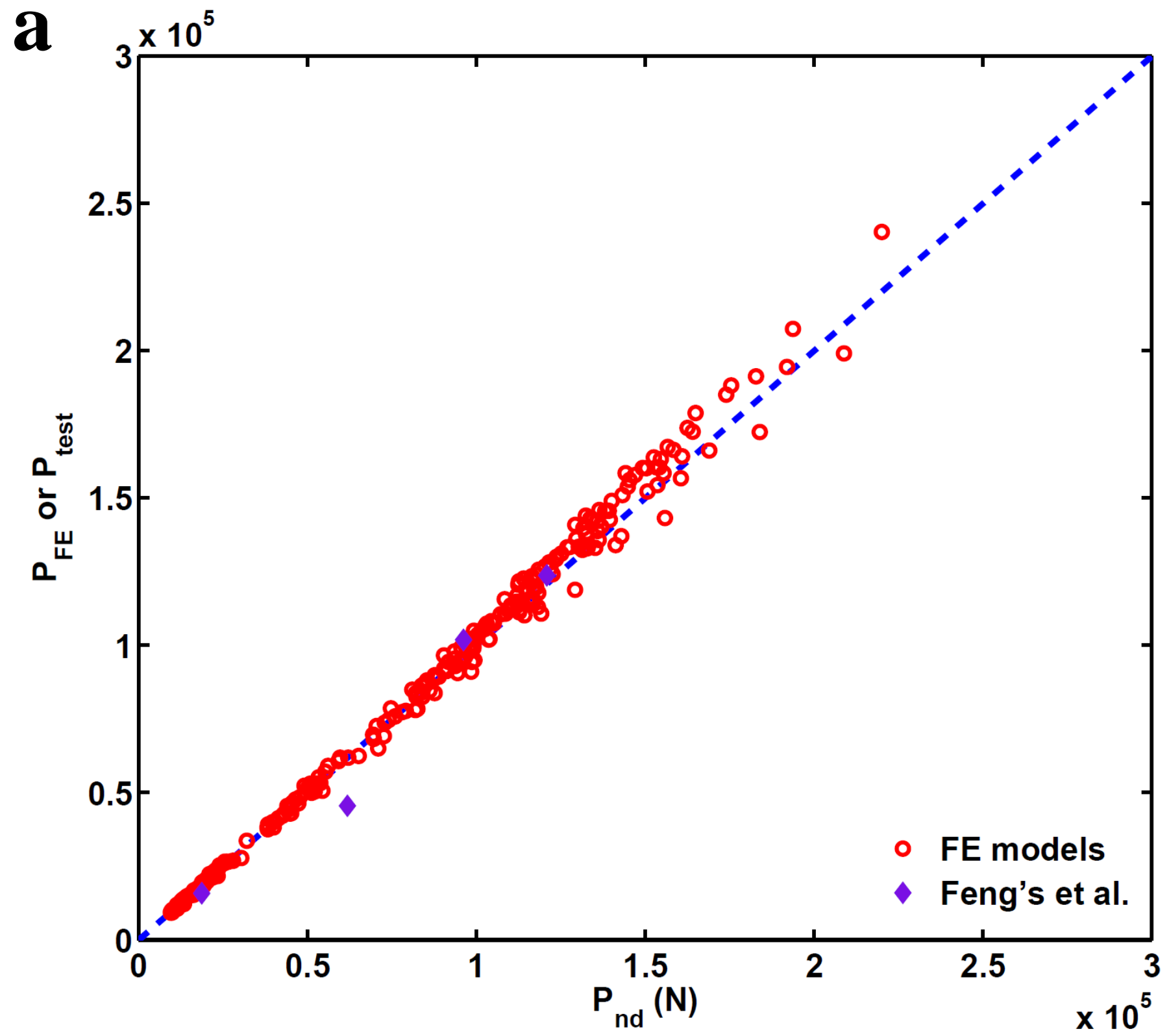




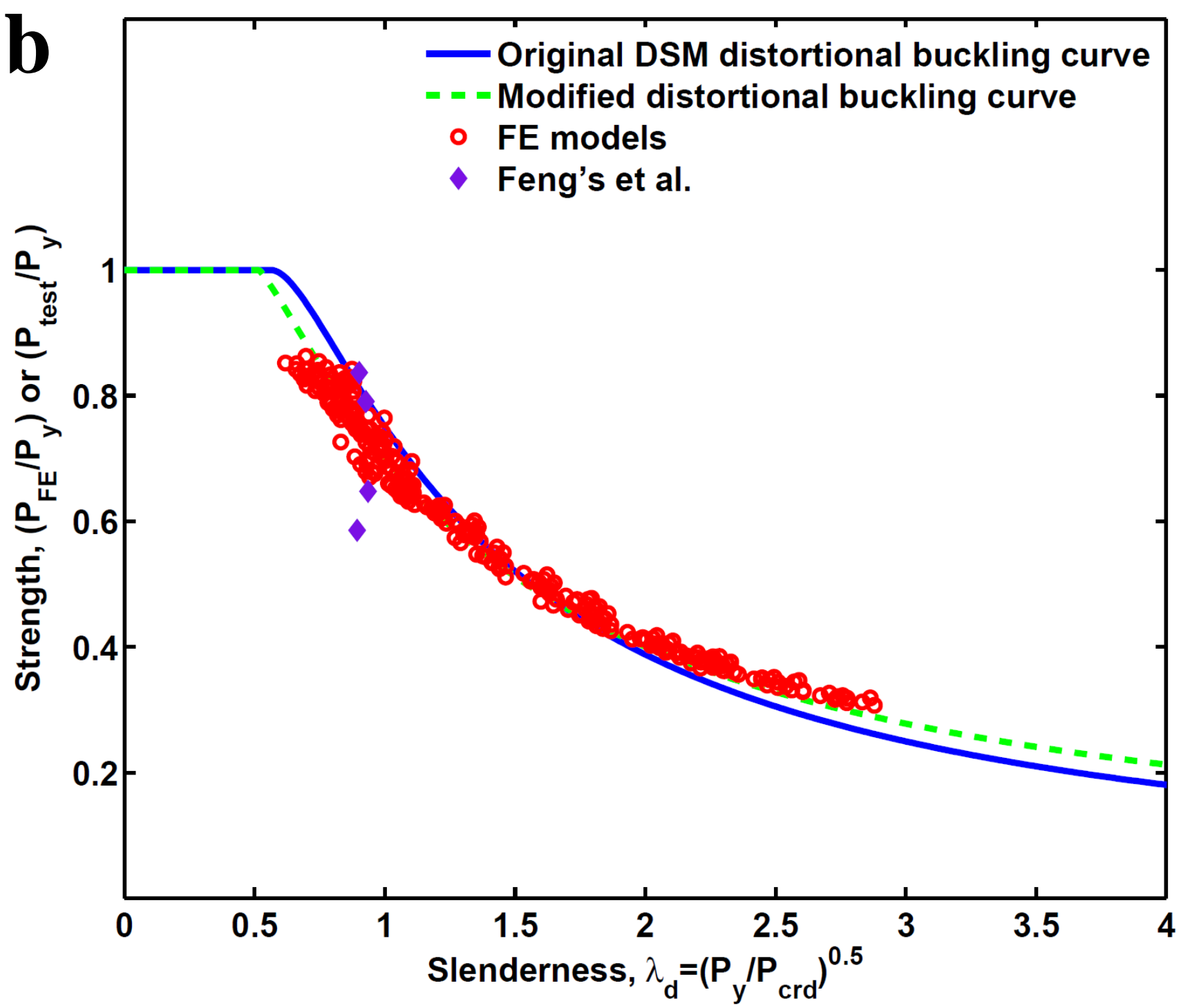

Figure 12. Comparison between original and modified DSM calculation results with FE Simulations of this study and results of Fengs et al. [12] for uniform elevated temperature; (a) column load-carrying capacity and (b) column loadcarrying capacity - slenderness relationship 


\subsection{Non-uniform elevated temperatures}

When a cold-formed thin-walled (CF-TW) steel member is exposed to fire from one side, the temperatures on the exposed side and unexposed sides will be different. Due to this non-uniform temperature distribution, the following two additional effects should be considered as observed in the experimental studies by Feng and Wang [23], the numerical studies by Feng et al. [22] and authors sensitivity study [3]:

- Thermal bowing caused by differential thermal expansion on the two sides of the cross-section (Figure 13a).

- Shift of centre of resistance due to non-uniform distribution of resistance (yield stress) of the steel (Figure 13b).

These effects will cause additional bending moments when the member is under compressive load and should be considered when calculating both the elastic buckling and squash loads.
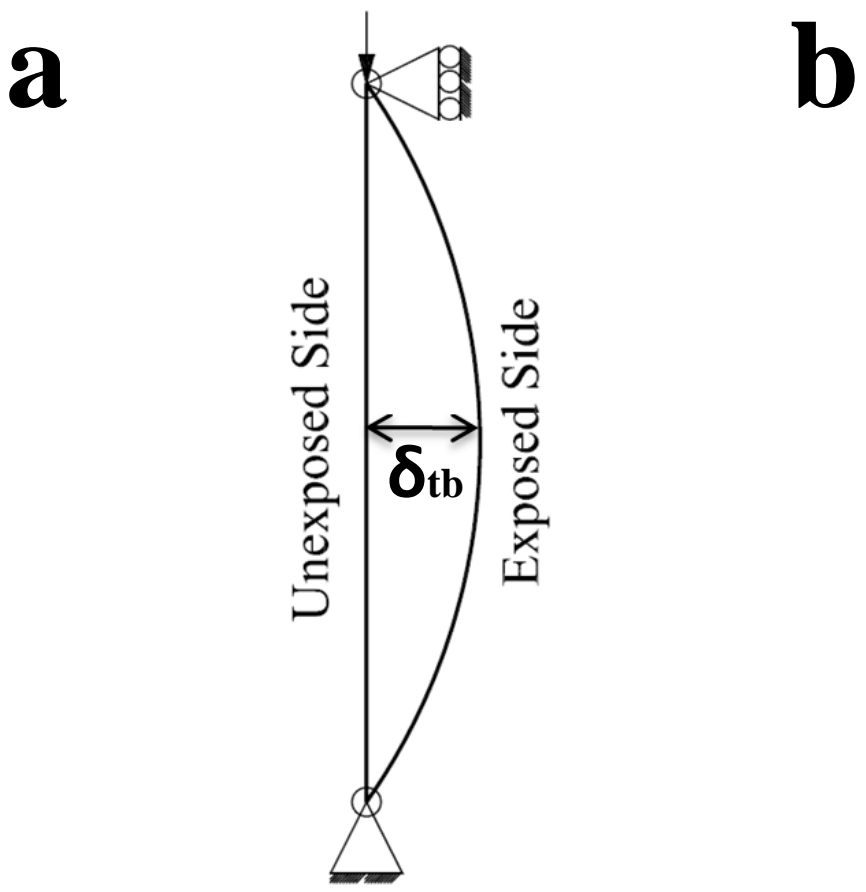

Exposed Side

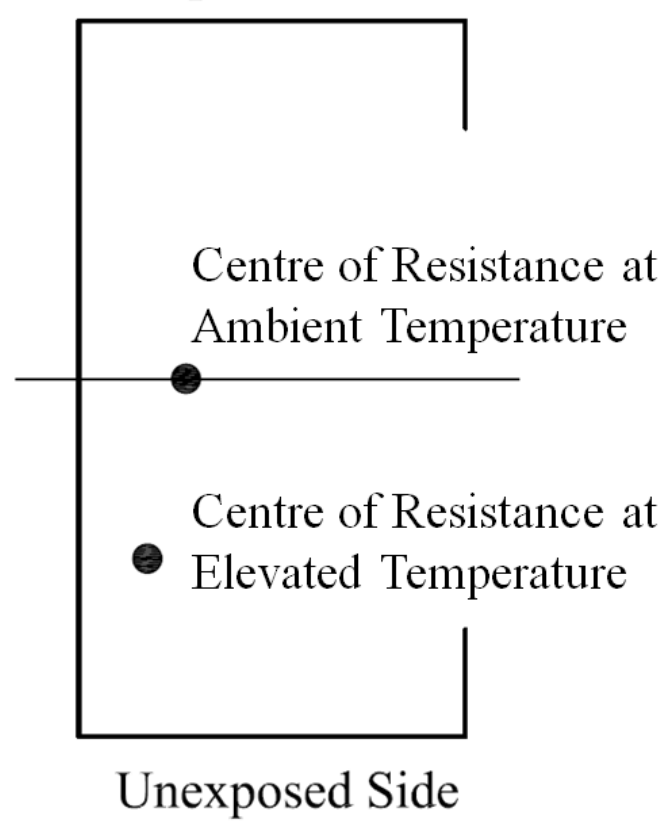

Figure 13. Addinitional bending moments caused by non-uniform temperature distribution in the cross-section; (a) thermal bowing, (b) shift of centre of resistance

The authors have recently developed a new methodology for calculating the elastic buckling and squash loads to take into consideration the above two effects. This method has been applied to thin-walled steel columns undergoing global buckling [3] and local buckling [4]. Details of this methodology can be found 
in Shahbazian and Wang [3]. A set of example calculations are provided in Appendix A to show how the method is applied. The same methodology has been applied to distortional buckling in this paper and is briefly explained as below.

For calculating the elastic buckling load, because the different strips have different mechanical properties corresponding to their different temperatures, it is not necessary to consider the shift in centre of resistance. However, the effect of thermal bowing should be explicitly considered as an additional bending moment.

The original column under pure axial load becomes a beam-column with combined axial load and bending moment as a result of the compressive axial load acting eccentrically from the centre of resistance of the cross-section with non-uniform temperature distribution. Therefore, the squash load of the member should be the axial load value that causes the cross-section with non-uniform temperature to reach the cross-section limit under combined axial load and bending. This is termed "effective" squash load in this study and is obtained using the following procedure [3]:

(1) Determine the plastic axial load - bending moment interaction curve of the cross-section. To do so, locate a neutral axis in the cross-section, which divides the cross-section into a tensile and a compressive part. Assume the cross-section has reached completely yield everywhere. The resulting stress distribution gives one value of axial load and one value of bending moment which is taken about the centre of resistance of the cross-section with non-uniform temperature distribution. Moving the neutral axis from one extreme side of the cross-section to the other gives the continuous plastic axial load-bending moment interaction curve of the cross-section.

(2) Since the top and bottom of the cross-section are fixed in position, there is no thermal bowing displacement so only a shift of the centre of resistance exists. In the middle of the column, both thermal bowing and the shift of the centre of resistance exist and they are in opposite directions. As a result, the bending moments at the ends and in the middle of the column are different. The effective squash load of the column is the one that gives the least value based on these two bending moments.

Figure 14 shows an interaction curve and how the effective squash load may be determined for one example long column. Having calculated the column effective squash load and the critical elastic distortional buckling load, the column ultimate strength for distortional buckling can be calculated using the DSM equations. Figure 15 compares the DSM calculation results with the ABAQUS simulation results. In the DSM calculations, the original distortional buckling curve (equation 2) was used. It clearly shows that the existing DSM equation for distortional buckling does not give sufficiently accurate results for columns with non-uniform temperature distributions, with the existing DSM curve tending to produce higher values, thus being on the unsafe side. However, the simulation results in Figure 15 are within a sufficiently close band at different slenderness, irrespective of the temperature and temperature gradient in the column cross-sections, indicating that it is feasible to use one distortional buckling curve for different non-uniform temperature distributions. The authors propose following relationship: 
for $\lambda_{d} \leq 0.561$

$$
P_{n d}=P_{y}
$$

for $\lambda_{d}>0.561$

$$
P_{n d}=0.65\left(1-0.14\left(\frac{P_{c r d}}{P_{y}}\right)^{0.7}\right)\left(\frac{P_{c r d}}{P_{y}}\right)^{0.7} P_{y}
$$

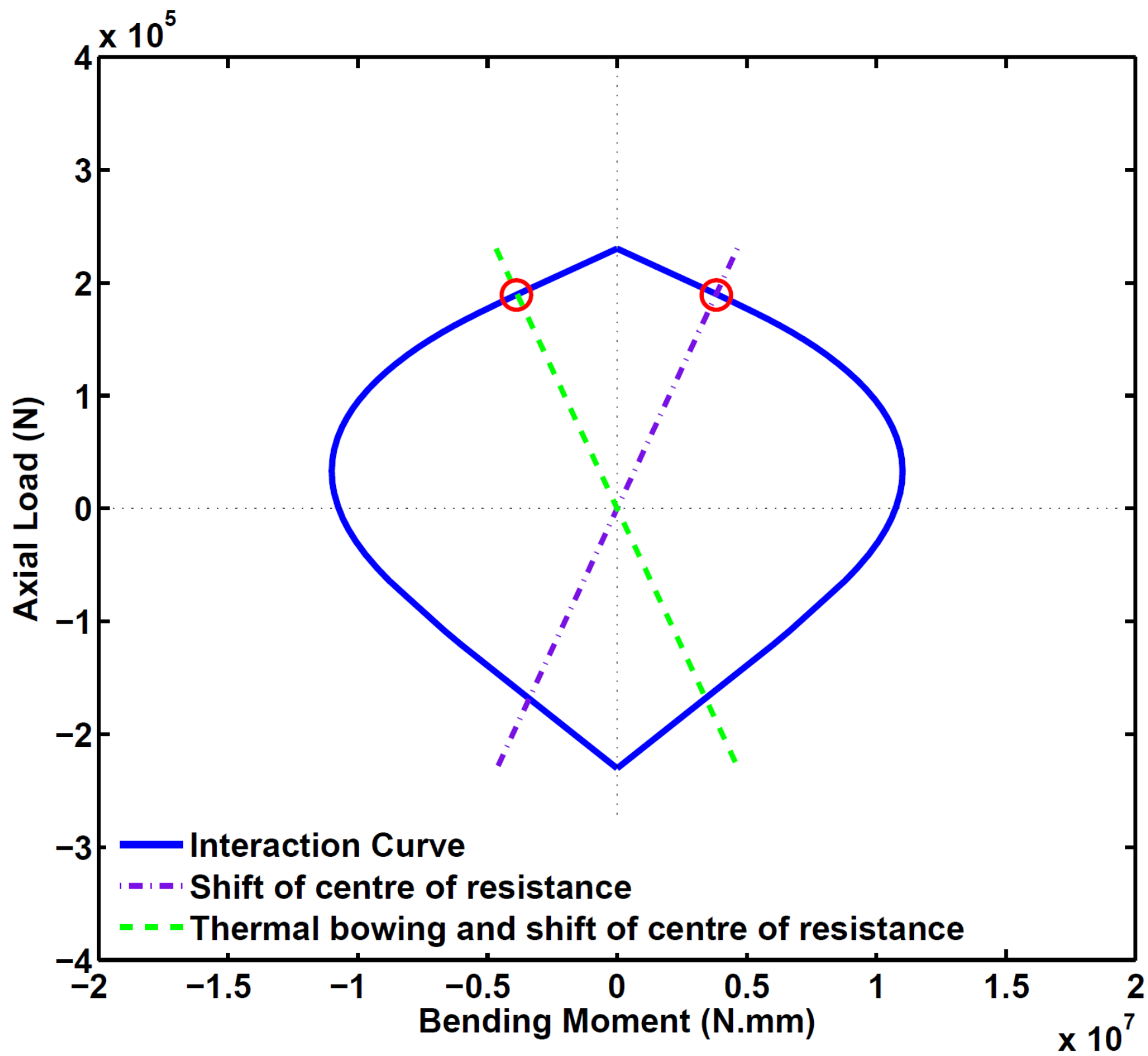

Figure 14. Determination of effective squash load for $\mathrm{LC150 \times 45 \times 13 \times 2.5}$ with $3000 \mathrm{~mm}$ length (temperature on exposed side: $5_{88}^{\circ} \mathrm{C}$ and on unexposed side: $203^{\circ} \mathrm{C}$ ) 


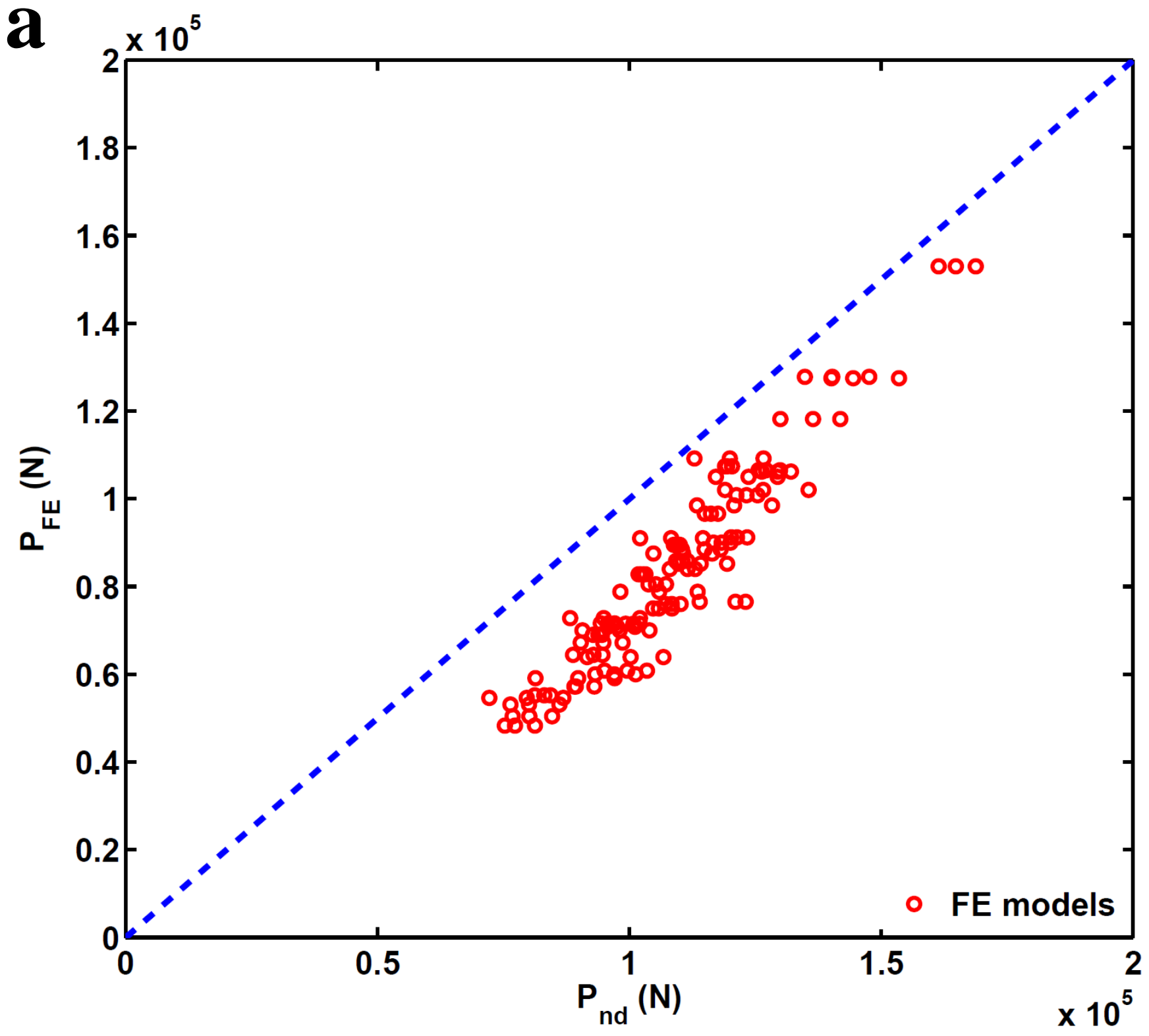




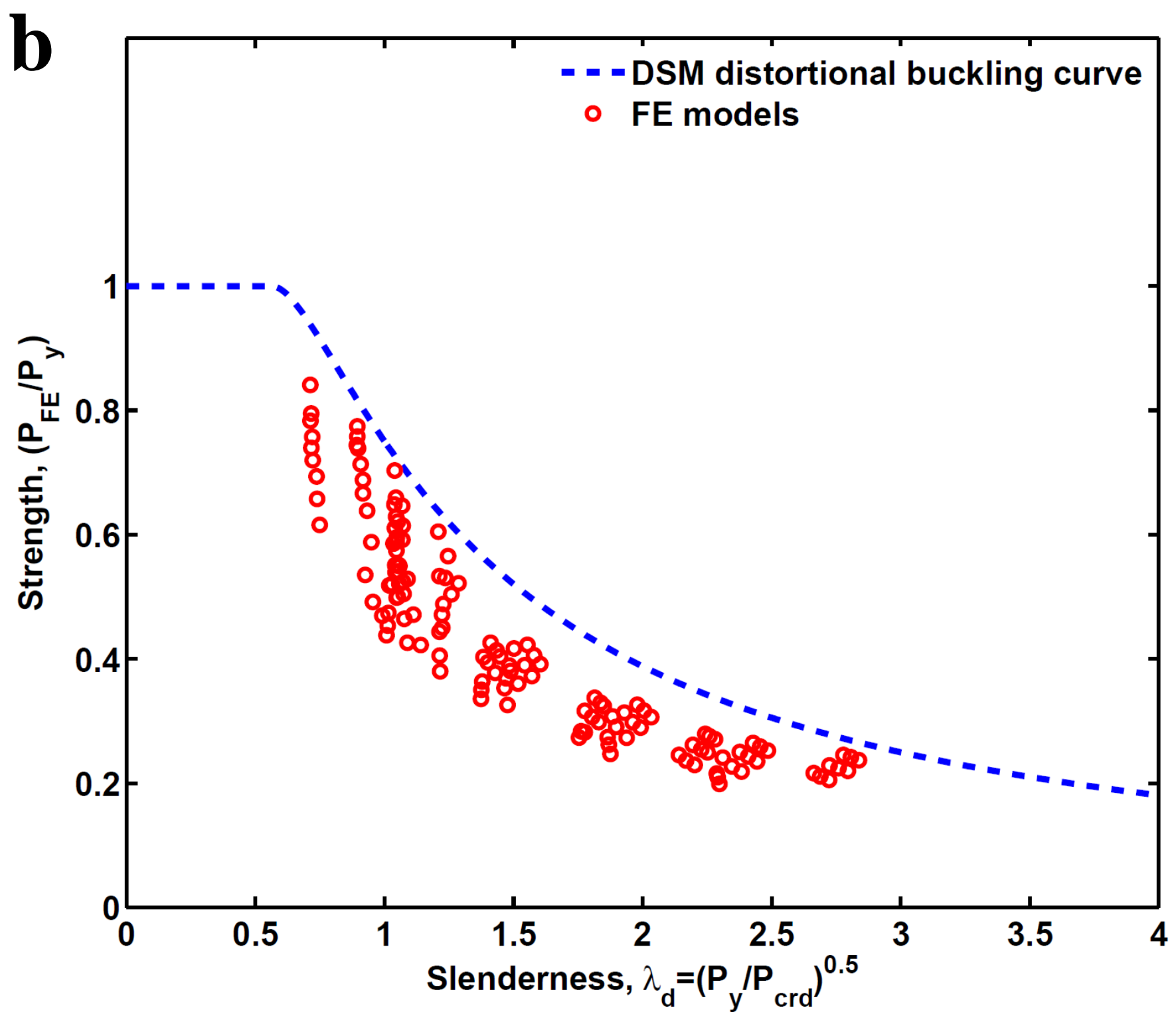

Figure 15. Comparison between original DSM calculation results with FE Simulations of this study for non-uniform elevated temperature; (a) column load-carrying capacity and (b) column load-carrying capacity - slenderness relationship

Figure 16 compares the FE simulation results with the DSM calculation results using the proposed new distortional buckling equation for the three different temperature profiles individually. The agreement between the FE simulation results and the DSM calculation results is good, and the average difference between the two sets of results is comparable for the three different temperature profiles $(14.73 \%$ for temperature profile 1 (1200/400), $14.10 \%$ for temperature profile $2(1200 / 600)$ and $13.93 \%$ for temperature profile 3 (1200/800). As shown in Figure 16, for each temperature profile, the simulation results are populated within a relatively narrow band, and indicate that the newly proposed distortional buckling curve for non-uniform temperature distributions is acceptable. 
This paper is the last of three papers by the authors to assess the applicability of the existing DSM equations to columns with non-uniform temperature distributions in the cross-sections. It has been found necessary to replace all three existing equations (1,2 and 3) by new equations (4, 5 and 7). Figure 17 shows the three new buckling curves (equations 4, 5 and 7) and compares them with the original DSM curves (equations 1-3) for ambient temperature design. 

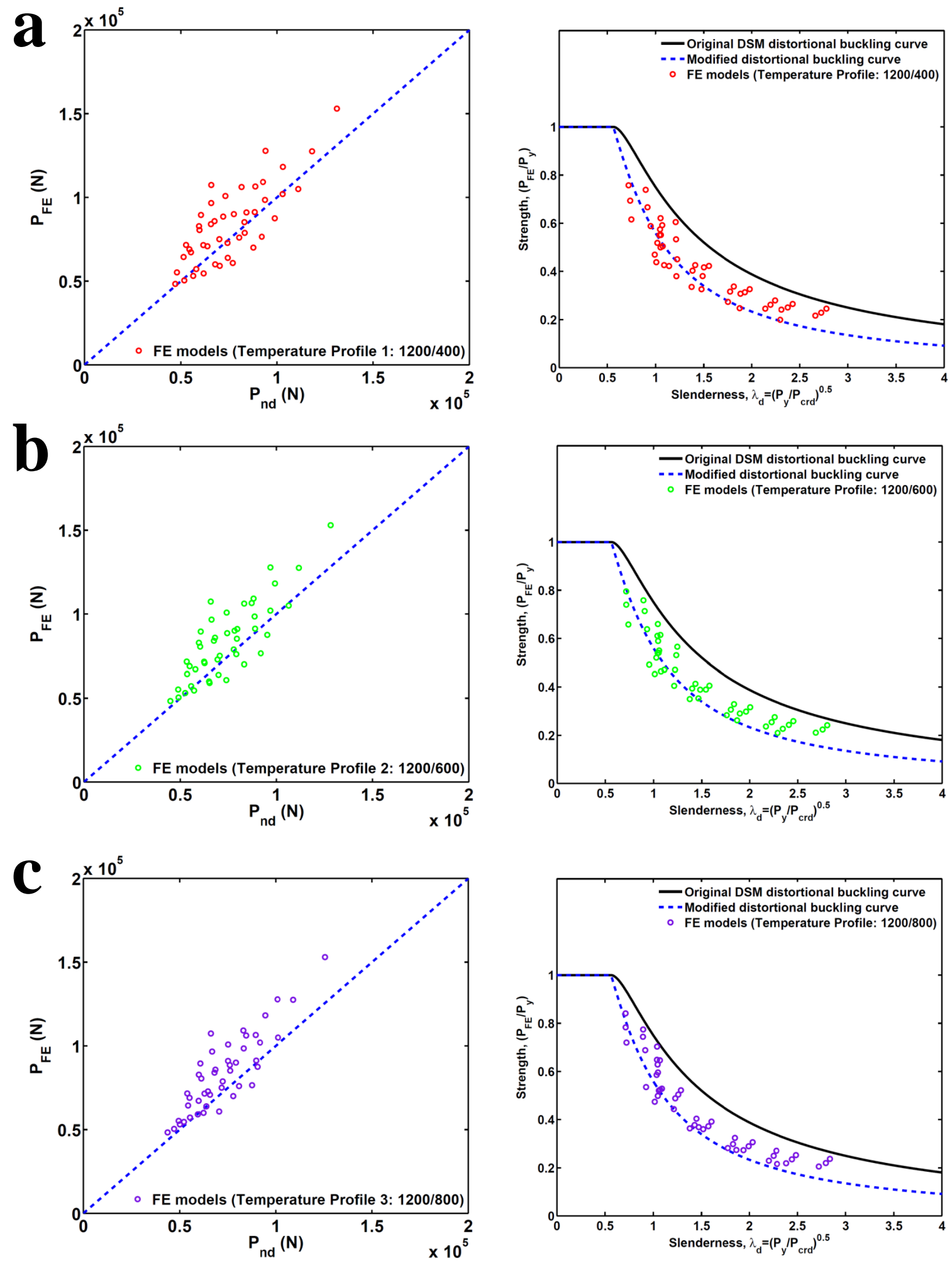
Figure 16. Comparison between FE simulation results with DSM calculation results for different temperature profiles using the newly proposed distortional buckling curve; (a) temperature profile 1 (1200/400 at 120 minutes), (b) temperature profile $2(1200 / 600$ at 120 minutes) and (c) temperature profile $3(1200 / 800$ at 120 minutes)

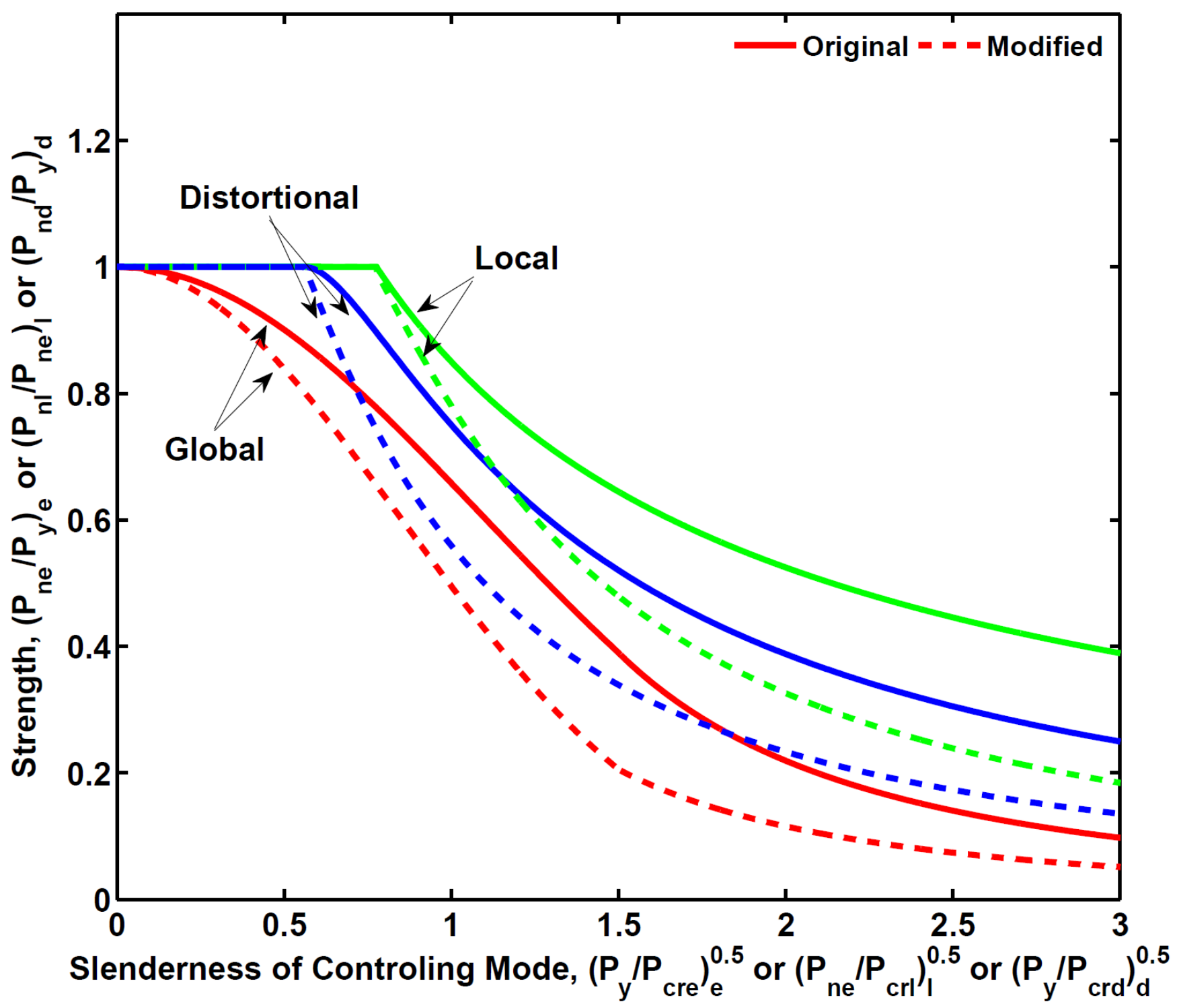

Figure 17. Comparison between the original DSM curves for ambient temperature design with the authors' modified DSM curves for columns with non-uniform temperature distributions in the cross-section 


\section{Conclusions}

This paper has presented the results of an extensive numerical simulation and analytical study to investigate the applicability of the Direct Strength Method to thin-walled steel columns with uniform and non-uniform temperature distributions in the cross-sections under distortional buckling. The following conclusions may be drawn:

(1) For uniform temperature applications, the DSM equations in AISI specification [2] are directly applicable, but there is a need for a small modification to improve the accuracy of the method. The proposed buckling curve is given in equation 6.

(2) For cross-sections with non-uniform temperature distributions, the DSM concept may still be applied, but a new distortional buckling curve should be used to replace the existing one (equation 2) for ambient temperature calculation. This new curve is expressed as equation 7.

(3) For global buckling [3], local buckling [4] and distortional buckling (this paper), the same method can be used to calculate the elastic buckling load and the plastic squash load of a column with non-uniform temperature in the cross-section. This method includes the effects of both thermal bowing and shift of the centre of resistance. 


\section{Appendix A}

This appendix uses an example to show detailed steps of the proposed calculation method.

\section{Cross-sectional plastic resistance}

Section dimensions:

$b_{\mathrm{w}}=150 \mathrm{~mm}, \mathrm{~b}_{\mathrm{f}}=45 \mathrm{~mm}, \mathrm{~b}_{\mathrm{l}}=13 \mathrm{~mm}, \mathrm{t}=2.5 \mathrm{~mm}$, length $=600 \mathrm{~mm}$

Mechanical properties:

$\mathrm{F}_{\mathrm{y}}=350 \mathrm{~N} / \mathrm{mm}^{2}, \mathrm{E}=205000 \mathrm{~N} / \mathrm{mm}^{2}$

Figure A1 shows the assumed temperature distribution: maximum temperature on the exposed side $=$ $479.63{ }^{\circ} \mathrm{C}$, minimum temperature on the unexposed side $=245.92{ }^{\circ} \mathrm{C}$. These temperatures correspond to those of the column at failure at an applied load of $76 \mathrm{kN}$ (load ratio 0.5) as determined by ABAQUS modelling. These temperatures were used to enable direct comparison between the calculated column strength with the ABAQUS simulation result. Figures A2 and A3 present the reduced steel elastic modulus and yield stress distributions in the cross-section according to the temperature distribution in Figure A1. The centre of resistance according to the yield stress distribution in Figure A3 is $65.49 \mathrm{~mm}$ from the lower temperature side ( $75 \mathrm{~mm}$ at ambient temperature). The shift of centre of resistance is 75 $65.49=9.51 \mathrm{~mm}$.

Thermal bowing:

$\delta_{\mathrm{tb}}=\frac{\alpha \mathrm{L}^{2} \Delta \mathrm{T}}{8 \mathrm{~d}}$

$\delta_{\mathrm{tb}}=$ bending moment caused by thermal bowing

$\alpha=$ thermal expansion coefficient $\left(0.000014 /{ }^{\circ} \mathrm{C}\right)$

$\mathrm{L}=$ column length

$\Delta \mathrm{T}=$ temperature difference between the exposed and unexposed sides of the cross-section

$\mathrm{d}=$ depth of the section $\left(\mathrm{b}_{\mathrm{w}}\right)$

Using the input data and temperature distribution in Figure A1, the thermal bowing is $0.98 \mathrm{~mm}$. Therefore, the effective squash load for the top and bottom of the column will be calculated using an eccentricity of $9.51 \mathrm{~mm}$ and that at the centre of the column using an eccentricity of 9.51-0.98 $=8.52 \mathrm{~mm}$. 


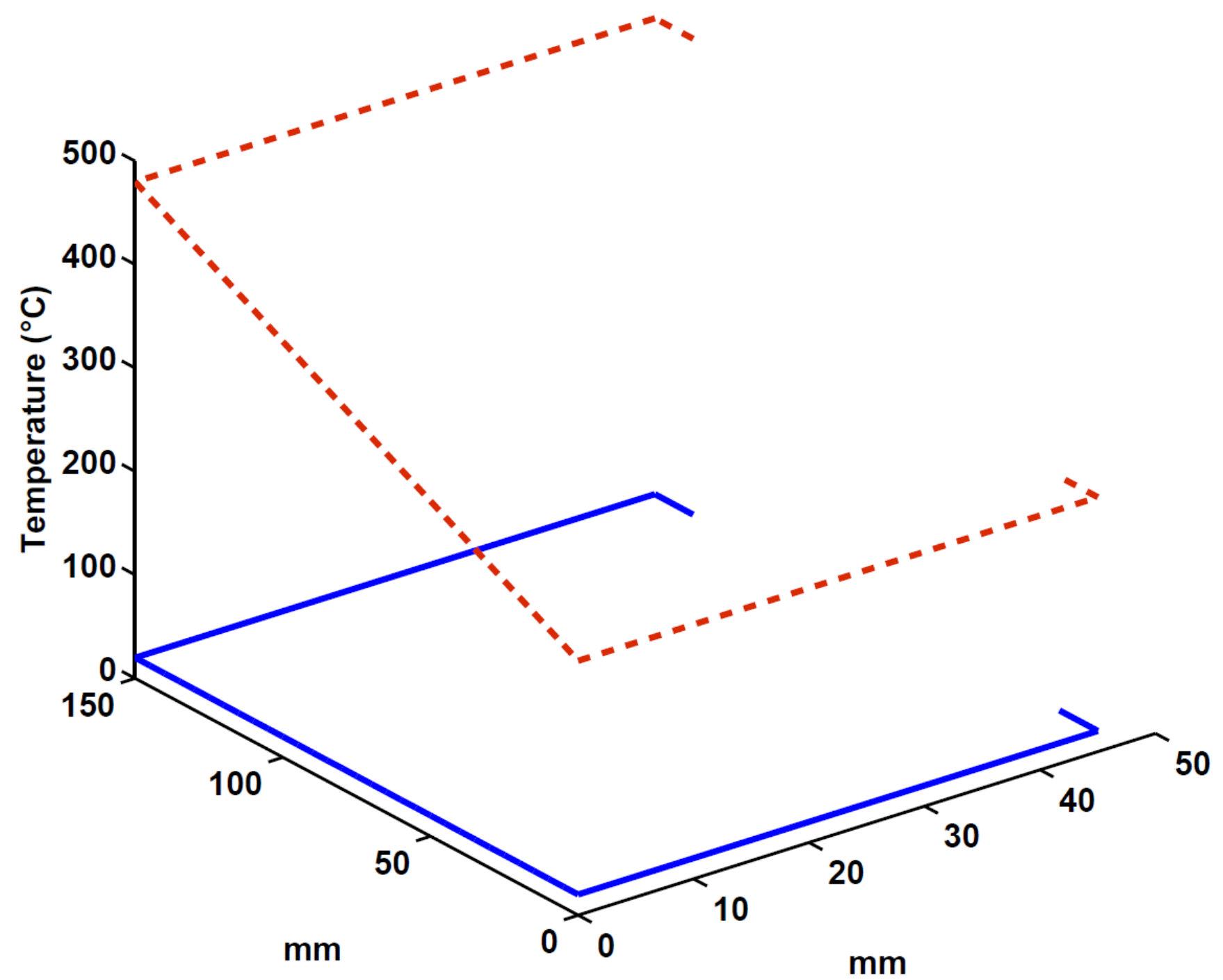

A 1. Temperatures in the cross-section; solid line indicates ambient temperature. 


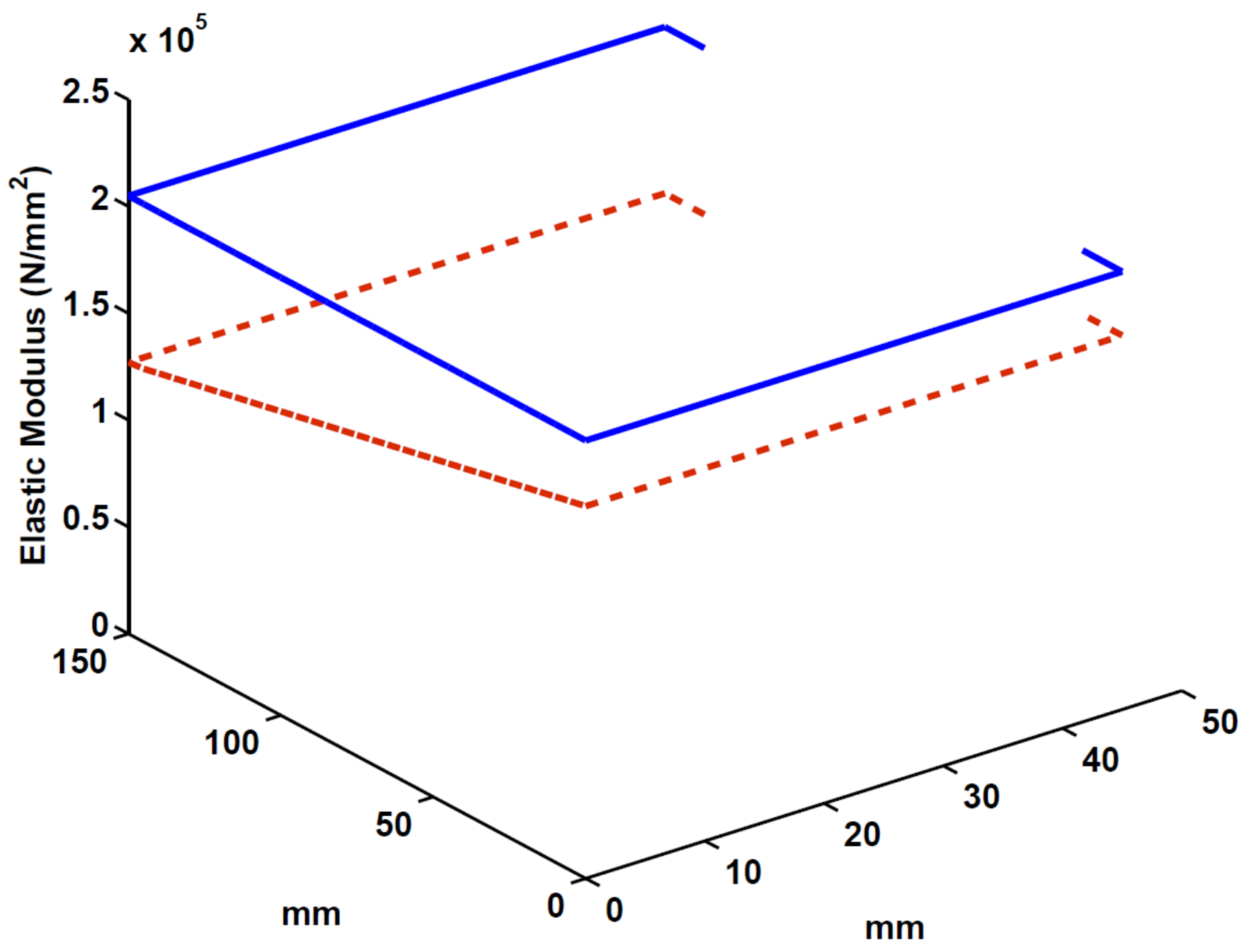

A 2. Elastic modulus distribution in the cross-section; solid line is for ambient temperature. 


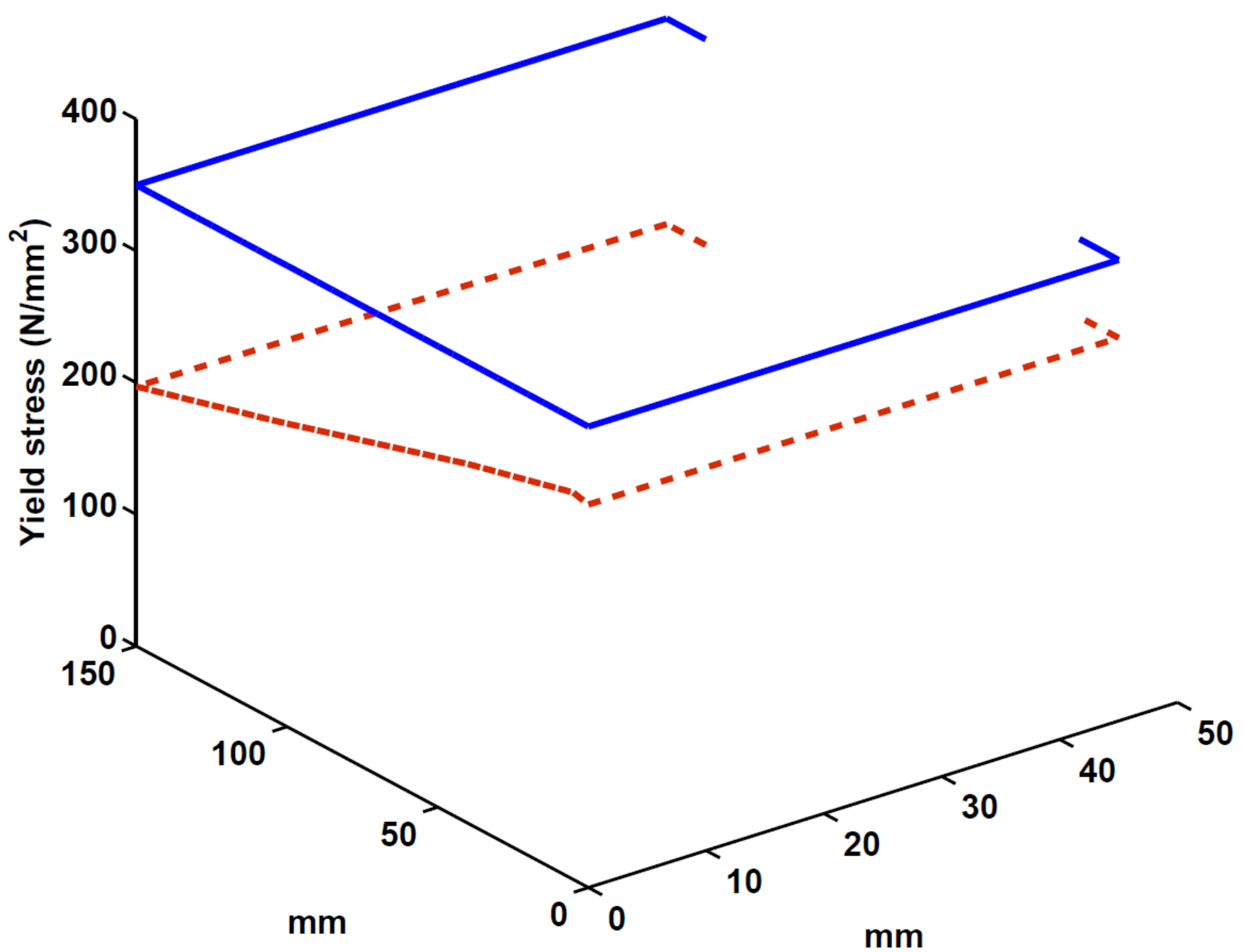

A 3. Yield stress distribution in the cross-section; solid line is at ambient temperature. 


\section{Effective squash load}

The column axial load-bending moment interaction curve is shown in Figure A4. The effective squash load corresponding to the two eccentricities are $146120 \mathrm{kN}$ (top and bottom) and 148230 (middle).

Therefore the effective squash load of the column is

$\mathrm{P}_{\mathrm{y}_{\mathrm{eff}}}=\min (146120,148230)=146120 \mathrm{~N}$

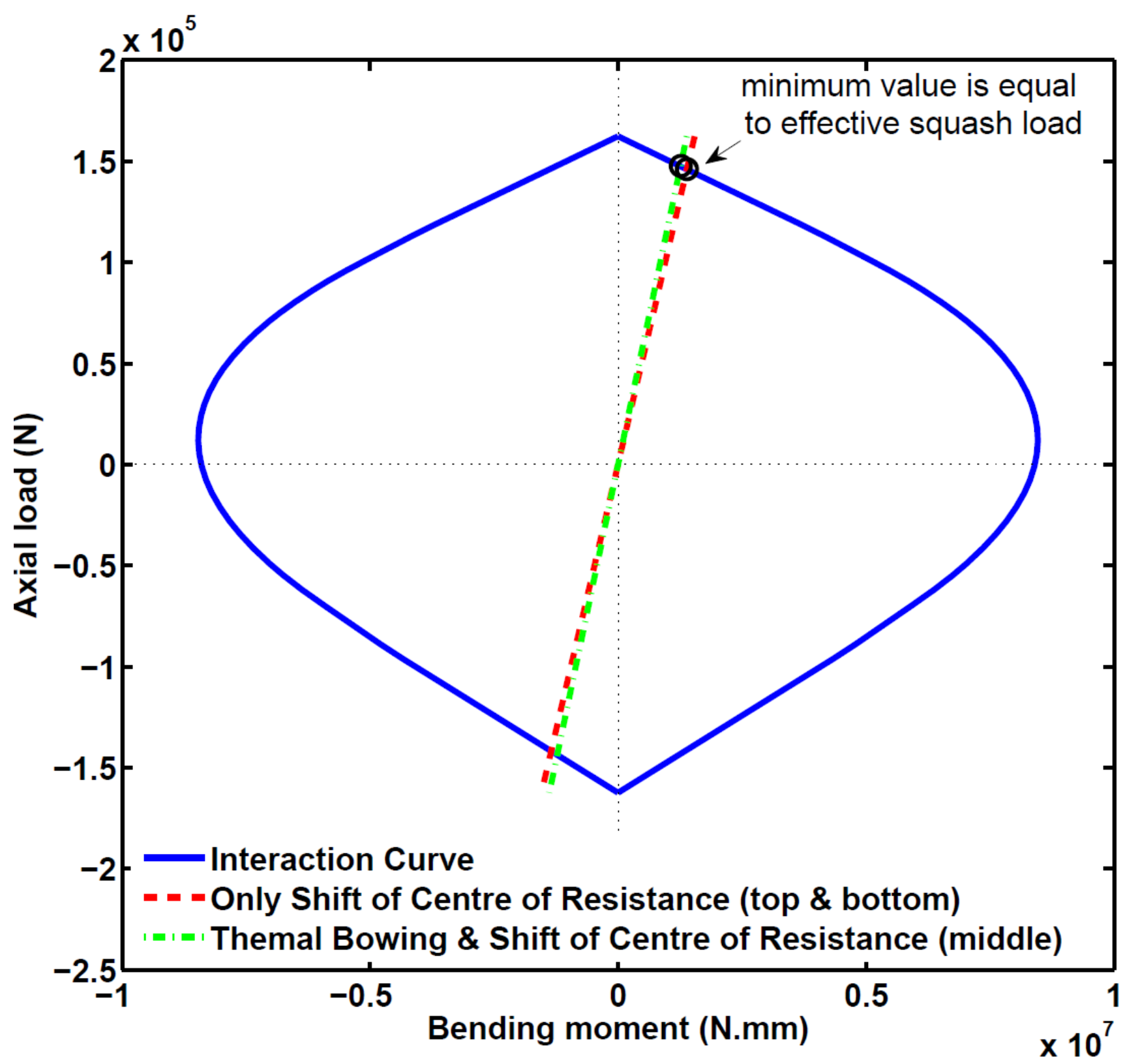

A 4. Effective squash load determination 


\section{$\underline{\text { Elastic buckling load }}$}

By dividing the cross-section into a number of small segments and inputting the varying mechanical properties and eccentricities due to thermal bowing into the CUFSM program, the critical elastic buckling load of the column can be calculated. The results are shown in Figure A5.

The elastic critical load for distortional buckling is $\mathrm{P}_{\text {crd }}=138223.67 \mathrm{~N}$.

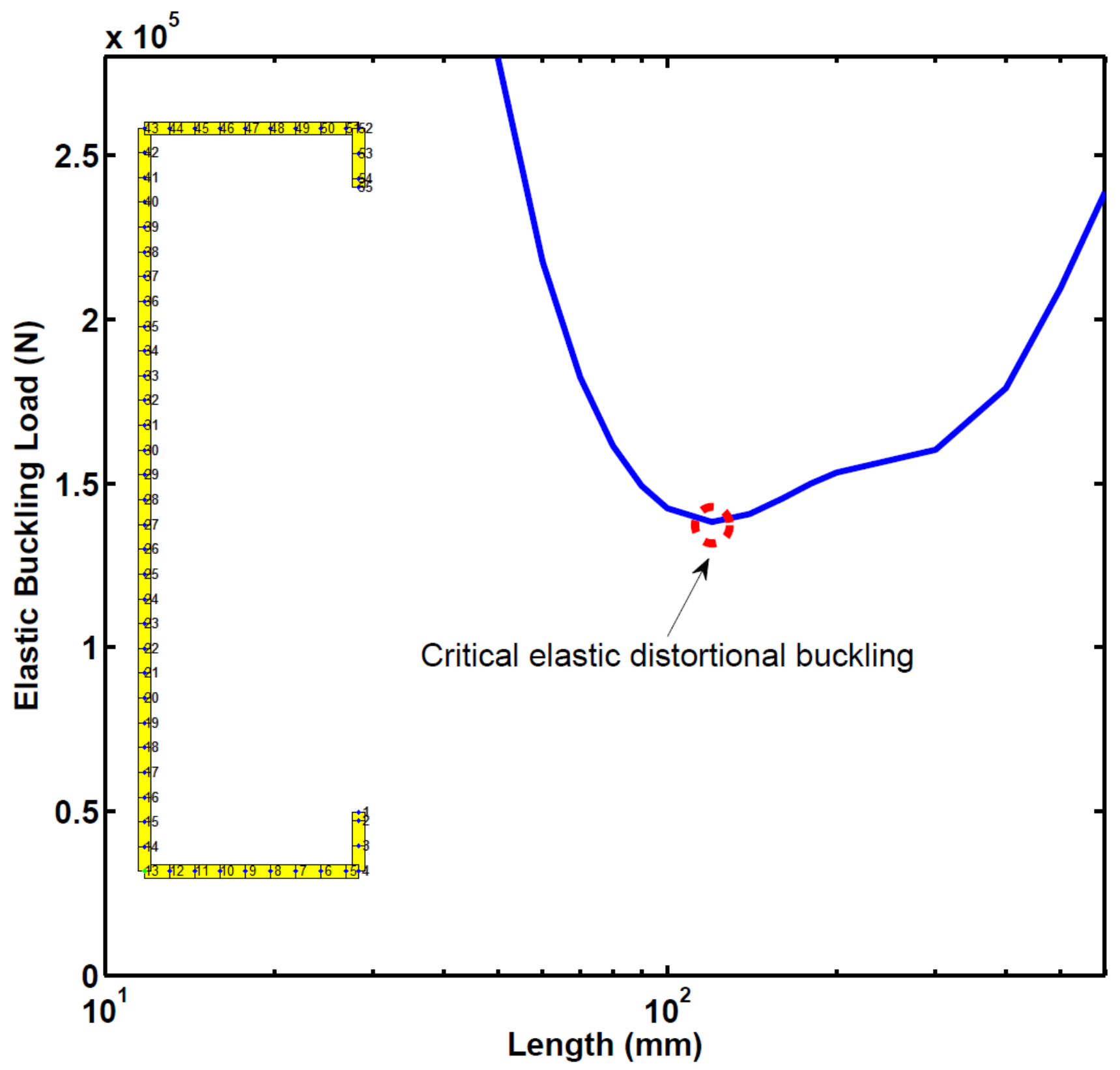

A 5. Division of cross-section into segments and elastic buckling curve from CUFSM 
Using equation 7 gives:

$\lambda_{d}=\sqrt{\frac{146120.00}{138223.67}}=1.02817$

$\mathrm{P}_{\mathrm{nd}}=0.65 *\left(1-0.14\left(\frac{138223.67}{146120.00}\right)^{0.7}\right) *\left(\frac{138223.67}{146120.00}\right)^{0.7} * 146120.00=79053.43 \mathrm{~N}$

(compare this with a failure load $P_{F E}=76000 \mathrm{~N}$ from $A B A Q U S$ ) 


\section{References}

[1] B.W. Schafer, Local, Distortional, and Euler Buckling of Thin-Walled Columns, Journal of Structural Engineering, 128 (2002) 289-299.

[2] AISI, North American Specification for the Design of Cold-Formed Steel Structural Members, American Iron and Steel Institute, Washington DC, 2007.

[3] A. Shahbazian, Y.C. Wang, Calculating the global buckling resistance of thin-walled steel members with uniform and non-uniform elevated temperatures under axial compression, Thin-Walled Structures, 49 (2011) 1415-1428.

[4] A. Shahbazian, Y.C. Wang, Application of the Direct Strength Method to local buckling resistance of thin-walled steel members with non-uniform elevated temperatures under axial compression, Thin-Walled Structures, 49 (2011) 1573-1583.

[5] B.W. Schafer, Review: The Direct Strength Method of Cold-Formed Steel Member Design, Journal of Construction Steel Research, 64 (2008) 766 - 778.

[6] C.D. Moen, B.W. Schafer, Direct Strength Method for Design of Cold-Formed Steel Columns with Holes, Journal of Structural Engineering, 137 (2011) 559-570.

[7] T. Sputo, J. Tovar, Application of direct strength method to axially loaded perforated cold-formed steel studs: Longwave buckling, Thin-Walled Structures, 43 (2005) 1852-1881.

[8] J. Tovar, T. Sputo, Application of direct strength method to axially loaded perforated cold-formed steel studs: Distortional and local buckling, Thin-Walled Structures, 43 (2005) 1882-1912.

[9] M. Feng, Y.C. Wang, J.M. Davies, A numerical imperfection sensitivity study of cold-formed thinwalled tubular steel columns at uniform elevated temperatures, Thin-Walled Structures, 42 (2004) 533555.

[10] M. Feng, Y.C. Wang, J.M. Davies, Thermal performance of cold-formed thin-walled steel panel systems in fire, Fire Safety Journal, 38 (2003) 365-394.

[11] M. Feng, Y.C. Wang, J.M. Davies, Structural behaviour of cold-formed thin-walled short steel channel columns at elevated temperatures. Part 2: Design calculations and numerical analysis, ThinWalled Structures, 41 (2003) 571-594.

[12] M. Feng, Y.C. Wang, J.M. Davies, Structural behaviour of cold-formed thin-walled short steel channel columns at elevated temperatures. Part 1: experiments, Thin-Walled Structures, 41 (2003) 543570 .

[13] O. Kaitila, Finite Element Modelling of Cold-Formed Steel Members at High Temperatures, in: Department of Civil and Environmental Engineering, Helsinki University of Technology 2002.

[14] O. Kaitila, Imperfection sensitivity analysis of lipped channel columns at high temperatures, Journal of Constructional Steel Research, 58 (2002) 333-351.

[15] Y.B. Heva, M. Mahen, Local Buckling Tests of Cold-Formed Steel Compression Members at Elevated Temperatures, in: Proceedings 5th International Conference on Thin-Walled Structures, Gold Coast, Australia, 2008, pp. 745-752.

[16] T. Ranawaka, M. Mahendran, Numerical modelling of light gauge cold-formed steel compression members subjected to distortional buckling at elevated temperatures, Thin-Walled Structures, 48 (2010) 334-344.

[17] T. Ranawaka, M. Mahendran, Distortional Buckling Tests of Cold-Formed Steel Compression Members at Elevated Temperatures, Construction Steel Research, 65 (2009) 249-259.

[18] J. Chen, B. Young, Experimental Investigation of Cold-Formed Steel Material at Elevated Temperatures, Thin-Walled Structures, 45 (2007) 96-110.

[19] J. Chen, B. Young, Cold-formed steel lipped channel columns at elevated temperatures, Engineering Structures, 29 (2007) 2445-2456.

[20] J. Chen, B. Young, Design of high strength steel columns at elevated temperatures, Journal of Constructional Steel Research, 64 (2008) 689-703. 
[21] M. Feng, Y.C. Wang, Cold-Formed Thin-Walled Steel Structures in Fire, The Structural Engineer, 80 (2002) 26-27.

[22] M. Feng, Y.C. Wang, J.M. Davies, Axial strength of cold-formed thin-walled steel channels under non-uniform temperatures in fire, Fire Safety Journal, 38 (2003) 679-707.

[23] M. Feng, Y.C. Wang, An experimental study of loaded full-scale cold-formed thin-walled steel structural panels under fire conditions, Fire Safety Journal, 40 (2005) 43-63.

[24] CEN, Eurocode 3: Design of Steel Structures - Part 1-2: General Rules - Structural Fire Design, in: EN1993-1-2:2005, European Standard, Brussels, 2005.

[25] ABAQUS, v6.10 Documentation, Dassault Systèmes Simulia Corp., 2010.

[26] B.W. Schafer, S. Adany, Buckling Analysis of Cold-Formed Steel Members using CUFSM:

Conventional and Constrained Finite Strip Methods, in: 18th International Specialty Conference on ColdFormed Steel Structures, Florida USA, 2006. 